\title{
Integrative transcriptomic and metabolomic analysis of D-leaf of seven pineapple varieties differing in N-P-K\% contents
}

Jing Chen ${ }^{1,2^{*}}$, Hui Zeng ${ }^{1,2}$ and Xiumei Zhang ${ }^{1,2}$

\begin{abstract}
Background: Pineapple (Ananas comosus L. Merr.) is the third most important tropical fruit in China. In other crops, farmers can easily judge the nutritional requirements from leaf color. However, concerning pineapple, it is difficult due to the variation in leaf color of the cultivated pineapple varieties. A detailed understanding of the mechanisms of nutrient transport, accumulation, and assimilation was targeted in this study. We explored the D-leaf nitrogen ( $N$ ), phosphorus (P), and potassium (K) contents, transcriptome, and metabolome of seven pineapple varieties.

Results: Significantly higher N, P, and K\% contents were observed in Bali, Caine, and Golden pineapple. The transcriptome sequencing of 21 libraries resulted in the identification of 14,310 differentially expressed genes in the D-leaves of seven pineapple varieties. Genes associated with $\mathrm{N}$ transport and assimilation in D-leaves of pineapple was possibly regulated by nitrate and ammonium transporters, and glutamate dehydrogenases play roles in $\mathrm{N}$ assimilation in arginine biosynthesis pathways. Photosynthesis and photosynthesis-antenna proteins pathways were also significantly regulated between the studied genotypes. Phosphate transporters and mitochondrial phosphate transporters were differentially regulated regarding inorganic $P$ transport. WRKY, MYB, and bHLH transcription factors were possibly regulating the phosphate transporters. The observed varying contents of $\mathrm{K} \%$ in the D-leaves was associated to the regulation of $\mathrm{K}^{+}$transporters and channels under the influence of $\mathrm{Ca}^{2+}$ signaling. The UPLC-MS/MS analysis detected 873 metabolites which were mainly classified as flavonoids, lipids, and phenolic acids.
\end{abstract}

Conclusions: These findings provide a detailed insight into the N, P, K\% contents in pineapple D-leaf and their transcriptomic and metabolomic signatures.

Keywords: $\mathrm{Ca}^{2+}$ dependent $\mathrm{K}^{+}$transport, D-leaf, GS/GOGAT, K+ transport, Leaf color, N assimilation, NPK assimilation, $\mathrm{N}$ transport, Phosphate transporters, Photosynthesis

\section{Background}

Pineapple (Ananas comosus L. Merr.) is China's third most important tropical fruit, which is cultivated on about 70,000 hectares. In 2019, China ranked 5th in terms of pineapple production with 1727 thousand metric tons (www.statistica.com). Since the start of a

\footnotetext{
*Correspondence: chenjing@catas.cn

1 Key Laboratory of Tropical Fruit Tree Biology, Ministry of Agriculture,

Zhanjiang, Guangdong 524091, China

Full list of author information is available at the end of the article
}

special research program in 2006 in order to accelerate the developments in pineapple industry. One of the key research objectives is the plant nutrient and fertilizer management [1]. Studies have shown that the uptake of nitrogen $(\mathrm{N})$, phosphorus $(\mathrm{P})$, and potassium $(\mathrm{K})$ per day differs in different cultivars being cultivated in China. For example, Smooth Cayenne can uptake nearly $1 / 3$ rd more NPK as compared to Comte de Paris indicating different needs of fertilizers [1]. The differences in NPK contents are directly associated with the plant growth and development and fruit quality in different species. In apple, 
fruit quality, yield, and leaf micronutrients content varied with the applied NPK fertilizers [2]. The applied fertilizers can directly influence the nutrient concentrations in D-leaf of pineapple, which ultimately have positive influence on the yield and fruit size [3]. Particularly, the leaves either directly receive the sprayed nutrients or roots absorb the nutrients from soil, which are then translocated into the leaves and assimilated. Also, the leaf NPK contents directly influence the leaf photosynthetic capacity and thus affects overall growth and development and reproductive development in pineapple $[4,5]$.

Once absorbed by the plant roots in the form of ammonia or nitrate with the help of ammonium transporters (AMTs) and nitrate transporters (NRTs), $\mathrm{N}$ is transported to different plant organs and tissues. Once arrived it is assimilated through GS/GOGAT cycle (glutamine synthetase (GS) and glutamate synthase (GOGAT)) as well asparagine synthetase (AS), carbamoylphosphate synthase (CPsase), and mitochondrial glutamate dehydrogenase (GDH) [6]. Being prominent site of $\mathrm{N}$ assimilation, the leaf $\mathrm{N}$ content also depends on photosynthesis, carbon (C) metabolism, and amino acid synthesis [7]. Multiple studies have attempted to measure the differential $\mathrm{N}$ contents in different pineapple varieties cultivated across the globe $[1,4,8,9]$, however, the pathways and their differential regulation in this fruit plant have not been discovered in detail. Since, plants take up numerous nutrients (majorly $\mathrm{N}$ and $\mathrm{P}$ ) from soil, which are also transported and assimilated in leaves as well as other plant tissues [10]. Like $\mathrm{N}$ transporters, phosphate (inorganic phosphate, $\mathrm{Pi}$ ) is also transported from soil to the plants with the help of phosphate transporters (PHT) [11]. Other than PHTs, vacuolar phosphate transporters (VPTs), $\mathrm{Pi} / \mathrm{H}^{+}$antiporters also serve as Pi influx transporters into the vacuolar lumen [12,13]. Pi is not only stored in vacuole but also in chloroplasts and mitochondria. Several members of PHT family are localized in these two organelles e.g., PHT2, PHT3, and PHT4 [14, 15]. These PHTs are post-transcriptionally regulated by a number of a number of genes and transcription factors (TFs) including actin related protein 6 (ARP6), inositol pentakisphosphate 2 kinase 1 (IPK1), induced by phosphate starvation 1 (IPS1), WRKYs, MYB-type, and bHLH TFs [15-17]. Along with the $\mathrm{N}$ and $\mathrm{P}, \mathrm{K}^{+}$plays key roles in many processes in living cells and is considered indispensable for plant growth. $\mathrm{K}^{+}$is taken up by plant roots by Arabidopsis $\mathrm{K}^{+}$transporter 1 (AKT1) in a coordinated manner with calcineurin B-like (CBLs) and their interacting kinases (CIPKs) [18]. Apart from these, high affinity $\mathrm{K}^{+}$transporter 5 (HAK5), and $\mathrm{K}^{+}$uptake transporters (KUPs) are also a major transporter [19-21]. The root-absorbed- $\mathrm{K}^{+}$is translocated to aerial parts of the plants via xylem vessels. In this process, Stellar $\mathrm{K}^{+}$Outward Rectifier (SKOR) and Guard Cell Outwardly Rectifying $\mathrm{K}^{+}$channels (GORK) belonging to shaker family $\mathrm{K}^{+}$channels play major roles $[22,23]$. Once arrived in the leaves, $\mathrm{K}^{+}$is stored mostly stored in vacuole, where its sequestration is mediated by cation $/ \mathrm{H}^{+}$antiporters (NHXs) $[24,25]$ and the $\mathrm{K}^{+}$release (efflux) from vacuole is driven by the tandem por $\mathrm{K}^{+}$channels (TPKs) [26] Studies have also confirmed the involvement of $\mathrm{Ca}^{2+}$ signaling related genes in $\mathrm{K}+$ efflux and sequestration [27]. Apart from the selective transport and assimilation related genes and TFs, the leaf NPK contents have also been studied to be affected by cytokinins and auxin signaling. For example, in pineapple, it was reported that the endogenous levels of the phytohormones was significantly different in plant grown under medium with or without N [28]. However, a complete understanding on the above-mentioned transport and assimilation related genes, TFs, and pathways is scarce. Particularly, the existing varieties must be explored in order to develop a nutrition management strategy for individual varieties.

The need for NPK nutrition in plants can be easily detected from the leaf colour as in case of rice, maize, soybean, and other crops [29-31]. However, the famous cultivated varieties in China i.e., $\mathrm{BL}, \mathrm{CN}$, Golden pineapple (MD-2), and Tainong varieties (TN) were observed to have different leaf colors i.e., ranging from dark green to purple-green (See Methods section for details). Such a variation makes it difficult for farmers to estimate the NPK requirements of the plant, which is an easy task in other crop plants [29-31]. To this regard, there is very limited information available on the differential NPK contents in the leaves of the pineapple varieties that are being cultivated in China. Furthermore, there is no information available on the differential transcriptome and metabolomes in these varieties. Here, we attempted to check the NPK\% contents in the seven pineapple varieties i.e., $\mathrm{MD}-2, \mathrm{CN}, \mathrm{BL}, \mathrm{TN} 4$, TN17, TN21, and TN23, followed by transcriptome and metabolome profiling. In this study, we discussed the differential expression of key genes in transport and assimilation of N, P, and $\mathrm{K}$ in D-leaves of the selected pineapple variety. Furthermore, we also provide insights into the accumulated metabolites in the D-leaves of the studied pineapple varieties.

\section{Results}

\section{Variation in D-leaf $\mathrm{N}, \mathrm{P}$, and $\mathrm{K}$ contents}

Phenotypic appearance of the seven pineapple varieties clearly indicates that the leaves differ in their color appearance (Fig. 1a). Considering these differences, the $\mathrm{N}, \mathrm{P}$, and $\mathrm{K} \%$ contents in D-leaves were measured 


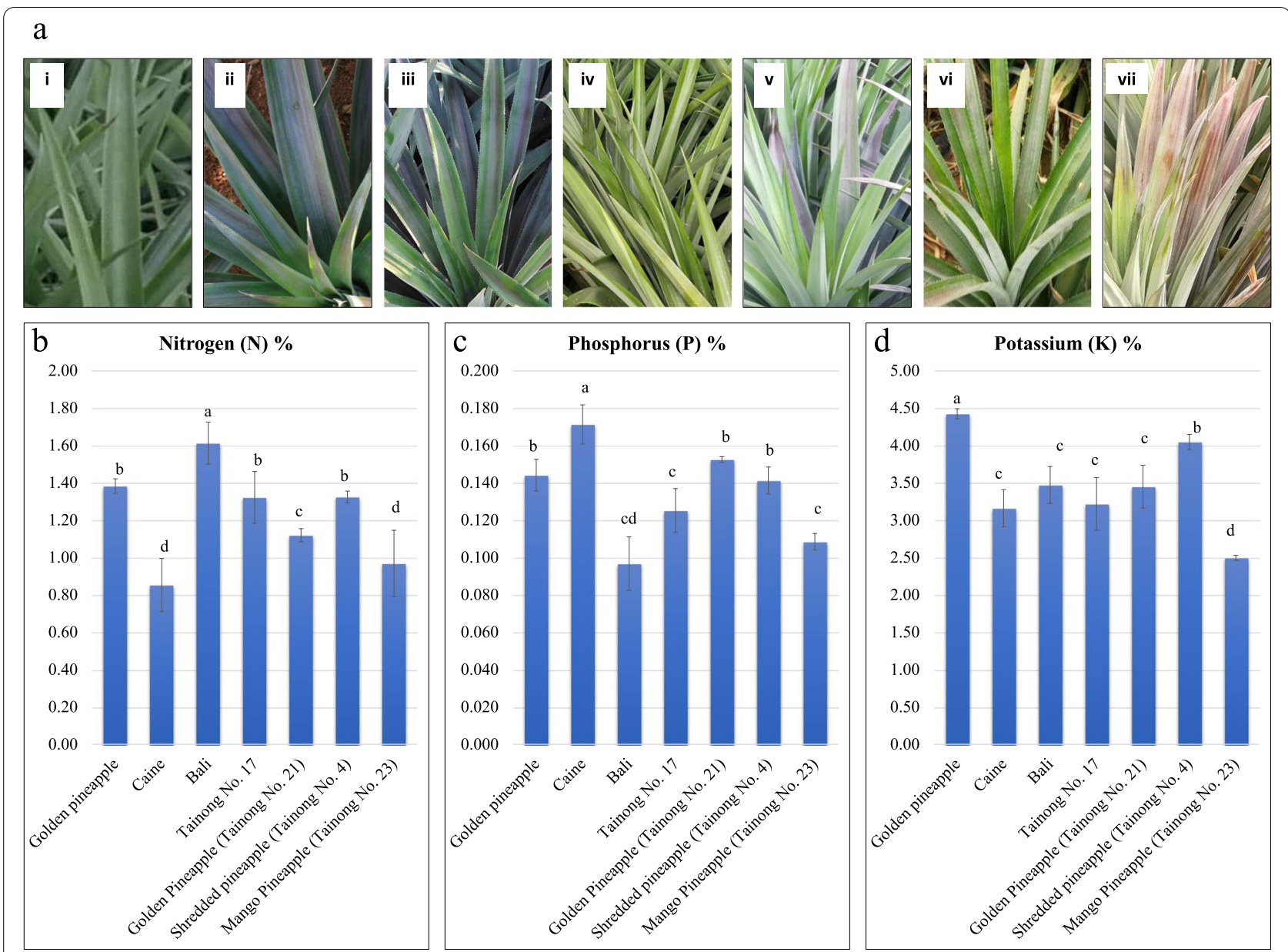

Fig. 1 a) Leaf color variation in seven pineapple varieties i.e., (i) Golden pineapple (MD-2), (ii) Caine (CN), (iii) Bali (BL), (iv) Tainong no. 21 (TN21), (v) Tainong no. 17 (TN17), (vi) Tainong no. 4 (TN4), and (vii) Tainong no. 23 (TN23). b) D-leaf nitrogen, c) phosphorus, and d) potassium percent contents in seven pineapple varieties. X-axes represent the tested varieties and Y-axis represent the $\%$ content of the nutrient. Different letters on the bars show that the varieties differ significantly for the nutrient percent content $(p<0.05)$

(Fig. 1b-d). Bali (BL) had significantly higher N\% among all the seven varieties followed by Golden pineapple (MD2), Tainong-17 (T17), Tainong-4 (T4), Tainong-21 (T21), Tainong-23 (T23), and Caine (CN, also known as Smooth Cayene) (Fig. 1b). CN had significantly higher P contents, while MD-2, T21, and T4 had similar P contents. Lowest $\mathrm{P}$ contents were recorded in BL and T23 (Fig. 1c). Highest and lowest $\mathrm{K}$ contents were observed in MD-2 and $\mathrm{T} 4$, respectively, while $\mathrm{CN}, \mathrm{BL}, \mathrm{T} 17$, and $\mathrm{T} 21$ had no significant differences. Second highest $\mathrm{K}$ content was measured in T4 (Fig. 1d). When summed up, the overall best $\mathrm{N}+\mathrm{P}+\mathrm{K} \%$ contents were highest in MD-2, followed by T4, BL, T21, T17, CN, and T23 (Supplementary Fig. 1). These observations suggest that $\mathrm{BL}, \mathrm{CN}$, and $\mathrm{MD}-2$ are best varieties from individual D-leaf nutrient content perspective.

\section{Transcriptome sequencing of D-leaves of seven pineapple} varieties

The transcriptome of 21 samples (three replicates of each variety) was sequenced using Illumina HiSeq Highthroughput sequencing platform. Clean read ranging from 44.82 to 80.08 million/sample (on average 54.44 million reads) were obtained from 21 Illumina libraries (Supplementary Table 1). A total of $169.1 \mathrm{~Gb}$ of clean data was obtained. The Q20 and Q30 base \%, and GC content $\%$ was $97.9 \%$, 94.09\%, and $50.71 \%$, respectively. Overall, on an average $91.54 \%$ reads could be mapped to the reference genome. Overall, FPKM values of $\mathrm{CN}, \mathrm{BL}$, and TN4 were higher than other varieties (Fig. 2a). The replicates of each variety tended to group together (Fig. 2b). Furthermore, the average PCC between the replicates and treatments was $>0.8$ (Fig. 2c). These observations 
a

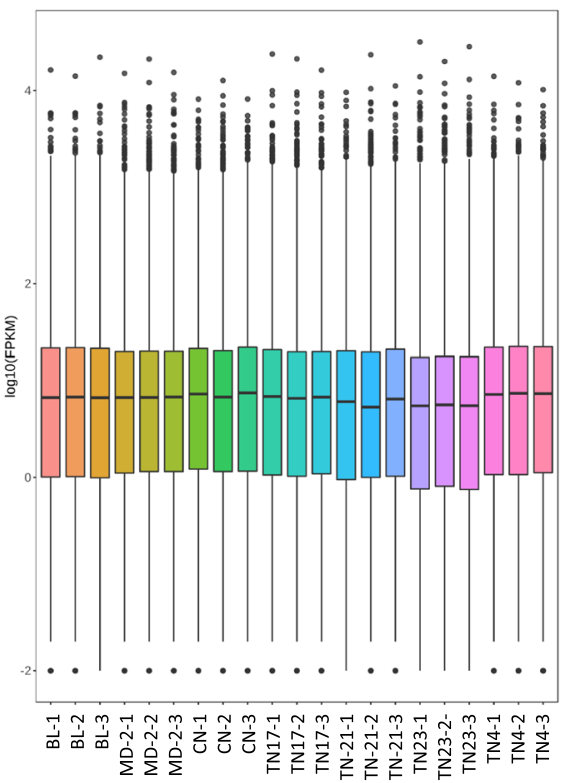

b

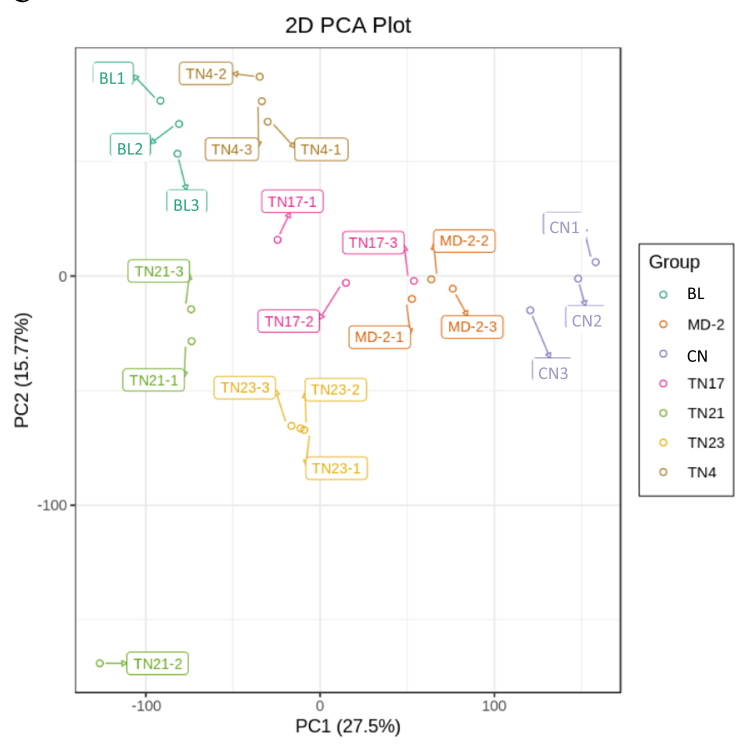

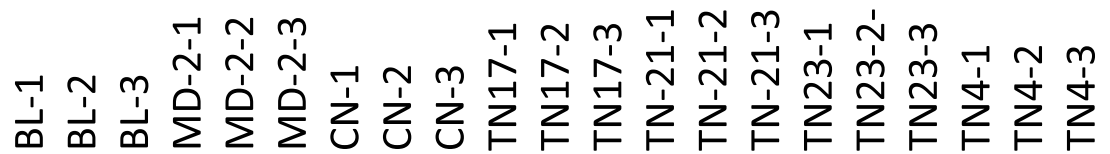

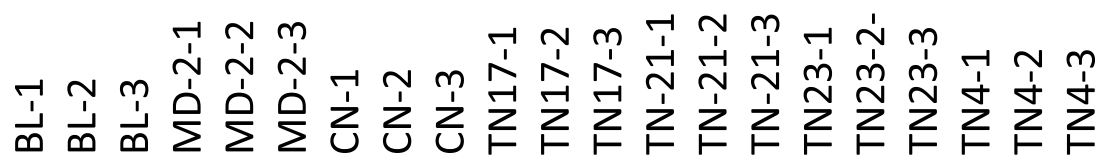

$\mathrm{BL}-1$

$\mathrm{BL}-2$

$\mathrm{BL}-3$

MD-2-1

MD-2-3 ( $(1)\left(\begin{array}{lllllllllllllllll}1 & 0.92 & 0.97 & 0.9 & 0.92 & 0.95 & 0.96 & 0.87 & 0.84 & 0.9 & 0.92 & 0.94 & 0.91 & 0.93 & 0.92 & 0.92\end{array}\right.$

CN-1

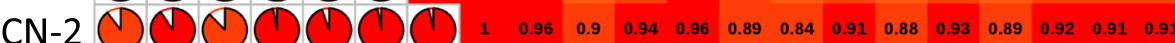

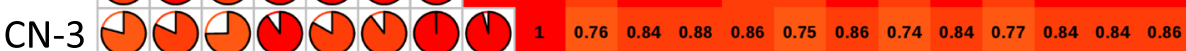

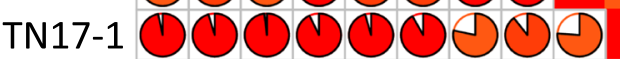

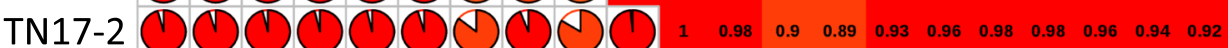

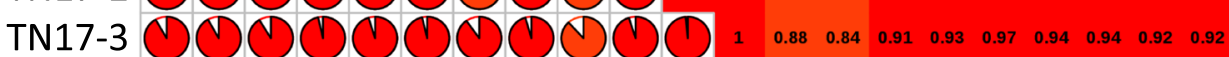

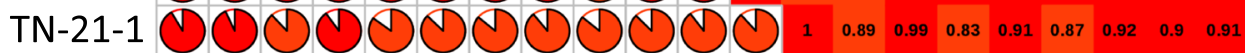

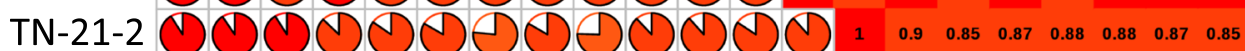

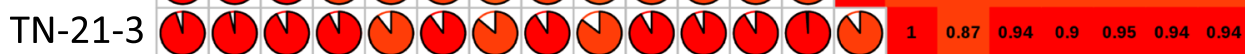

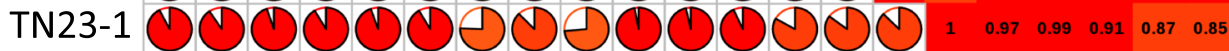

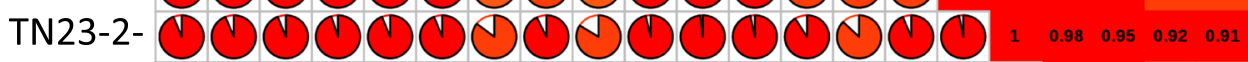

TN23-3

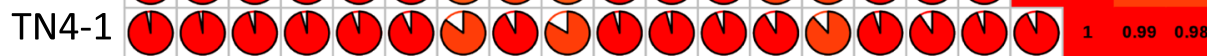

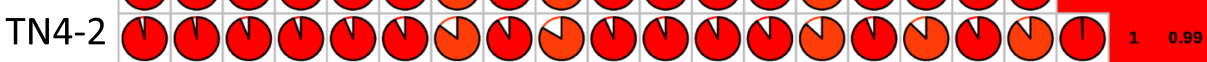

TN4-3 OOCOOOOOOOOOCOOOOOO

Fig. 2 Quantification of gene expression in D-leaves of seven pineapple verities. a Expressive bar plot representing overall distribution of gene expression. b Principal component analysis 2D plot. c Pearson Correlation Coefficients between biological replicates represented as a heatmap. Golden pineapple (MD-2), Caine (CN), Bali (BL), Tainong no. 4 (TN4), Tainong no. 17 (TN17), Tainong no. 21 (TN21), and Tainong no. 23 (TN23) 


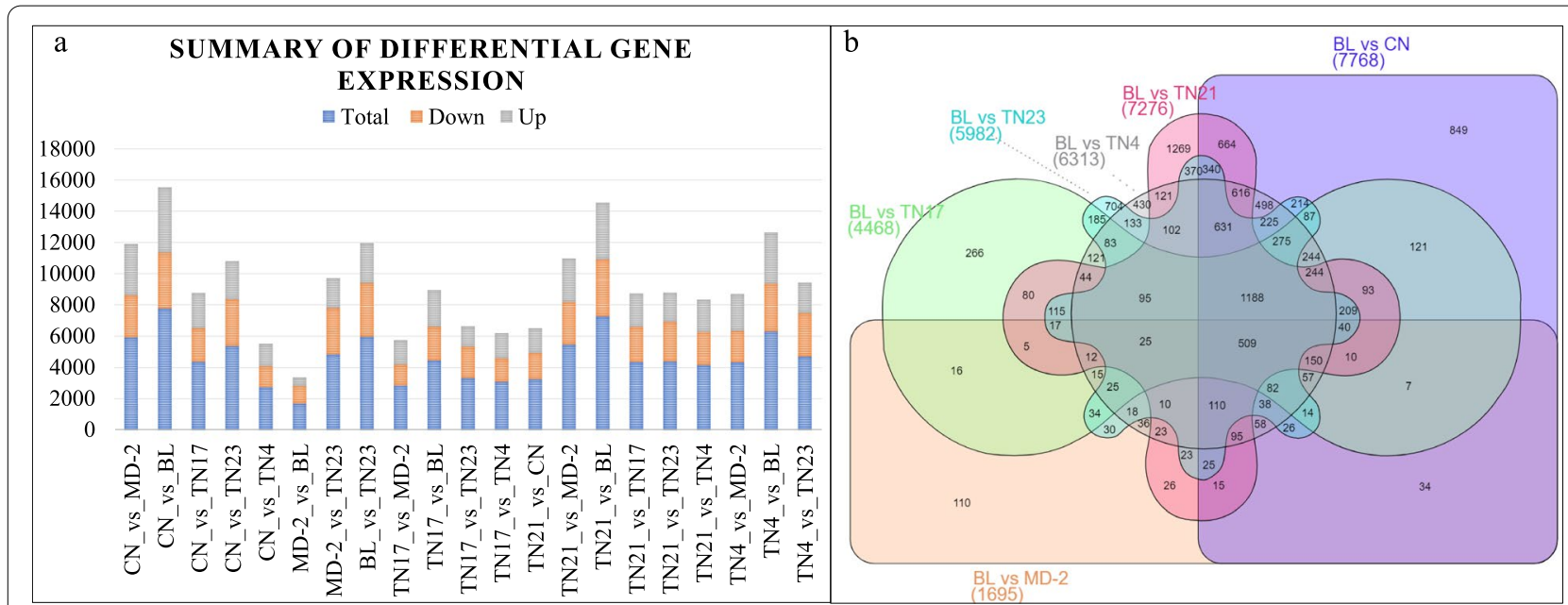

Fig. 3 a Summary of the differential gene expression in different pineapple variety comparisons. $\mathbf{b}$ Venn diagram showing the number of DEGs between BL versus other six pineapple varieties. Golden pineapple (MD-2), Caine (CN), Bali (BL), Tainong no. 4 (TN4), Tainong no. 17 (TN17), Tainong no. 21 (TN21), and Tainong no. 23 (TN23)

support that the expression results are reliable and have least variability between the replicates of each variety.

\section{Differential Gene Expression between seven pineapple varieties}

In order to screen the differentially expressed genes (DEGs), we used a criterion i.e., $\mid \log 2$ Fold Change $\mid>=$ 1 , and FDR $<0.05$. These screening conditions resulted in the identification of 14,310 DEGs in the studied pineapple D-leaves (Supplementary Table 2; Fig. 3a).

D-leaf transcriptome comparison of BL with other varieties Since the D-leaves of the BL variety had significantly high N\% contents, therefore, we compared the gene expression of BL with the rest of the varieties and completed subsequent results. There were $1695,7768,4468$, 6313, 7276, and 5982 DEGs in BL vs. MD-2, BL vs. $\mathrm{CN}, \mathrm{BL}$ vs. TN17, BL vs. TN4, BL vs. TN21, and BL vs. TN23, respectively (Fig. 3b). The DEGs were significantly enriched in different KEGG pathways associated with signaling (MAPK signaling), photosynthesis, photosynthesis-antenna proteins, and plant-pathogen interaction. Furthermore, the DEGs were also enriched in pathways associated with nitrogen mobilization and assimilation (see details below).

\section{Differential regulation of $\mathrm{N}$ transport, assimilation and related pathways}

Nitrogen is assimilated by GS/GOGAT cycle [32]. In this cycle several key players take part such as GS and GOGAT. Additionally, AS, CPSase, and GDH [6]. In the $\mathrm{BL}$ vs. other pineapple varieties comparisons, we observed the differential regulation of 30 genes that were associated with nitrogen assimilation pathway (Fig. 4a). First of all, we found that NRTs and AMTs were differentially expressed. The AMTs were not differentially expressed between BL and MD-2. Similarly, only one of four AMTs were differentially expressed between BL vs. TN17 as well as BL vs. TN23. In case of BL vs. CN, only two AMTs were differentially expressed. A high-affinity NRT-like (NRT2.1-L) showed increased expression in all pineapple varieties as compared to BL, while it didn't differentially express in BL vs. TN17. These observations suggest that the arrival of $\mathrm{N}$ in the pineapple $\mathrm{D}$-leaves differ in different varieties and is largely dependent on the expression of the AMTs and NRTs. We noticed that nitrate reductases $(\mathrm{NAD}(\mathrm{P}) \mathrm{H})(\mathrm{NRs})$ had variable expression in different varieties i.e., their expression was lower in MD-2 and TN17, whereas higher in $\mathrm{CN}$ and TN21. Regarding $\mathrm{N}$ metabolism and assimilation, glutamate dehydrogenase $(\mathrm{GDH})$, formamidase, nitrate reductase (NR), nitrite reductase (NiR), carbonic anhydrase (CA), GS, GOGAT, and asparagine synthase (AS) were differentially expressed in the D-leaves of the pineapple varieties (Fig. 4a and b). Specifically, four GS and a GOGAT showed different FPKM values in different pineapple varieties. These genes were not differentially expressed in BL vs. MD-2 and BL vs. TN17. GS had higher expression in CN, TN4, and TN21 as compared to BL. Contrastingly, TN23 had lower GS FPKM values. GOGAT was only differentially expressed in BL vs. TN17; higher expression in TN17 as compared to BL. These observations suggest that GS/GOGAT are not key players in pineapple D-leaf $\mathrm{N}$ content variation. Two $\mathrm{GDH}(\mathrm{NAD}(\mathrm{P})+)$ had contrasting 


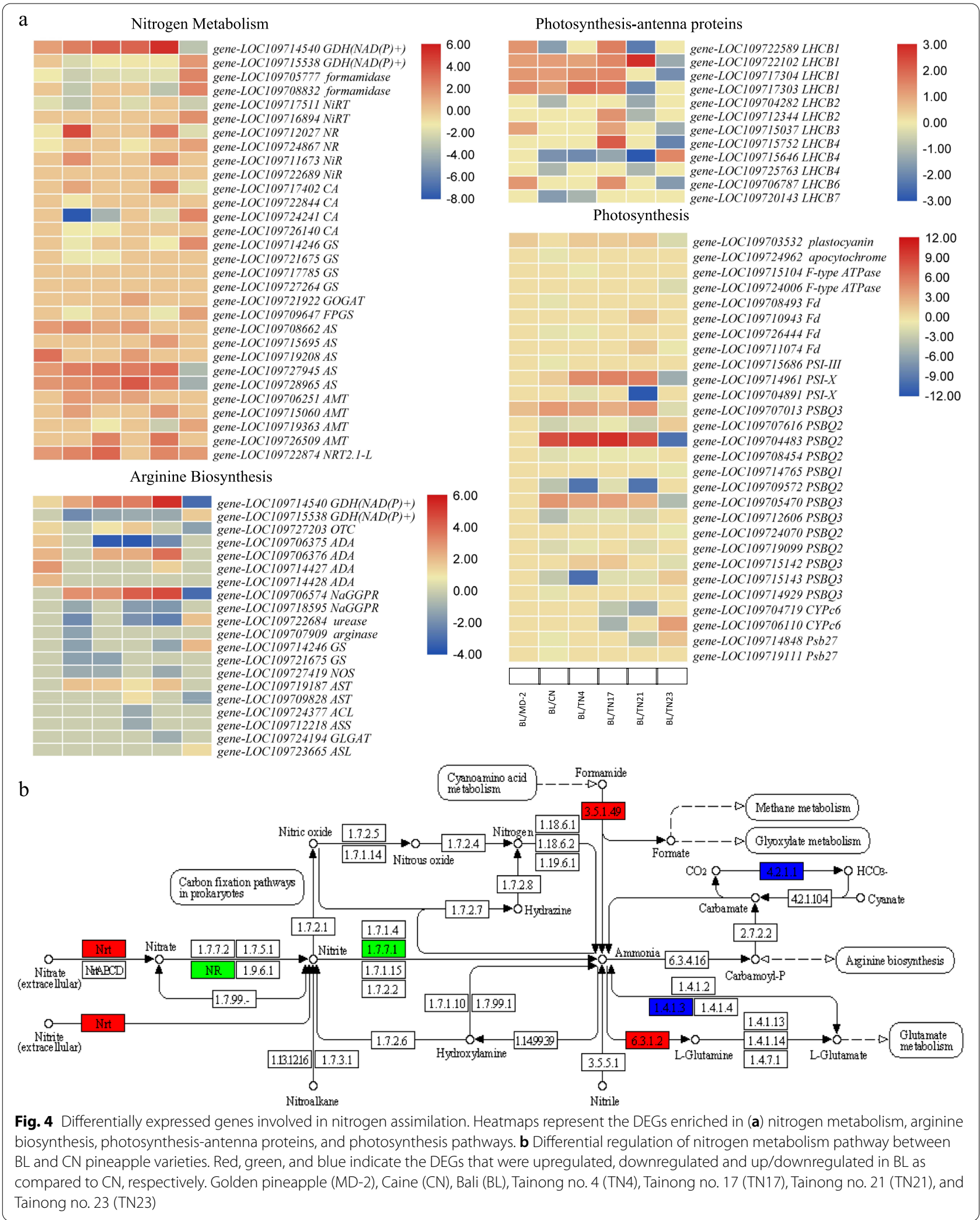


expression patterns in the $\mathrm{BL}$ vs. other variety comparisons; one (GDH2; gene-LOC109714540) was upregulated in all (except TN23) as compared to BL, while the second (GDH1; gene-LOC109715538) had contrasting expression. Thus, the variable $\mathrm{N}$ contents might be under the influence of both of these genes. Both GDHs play role in inducing changes in the contents of $\mathrm{C}$ and $\mathrm{N}$ as well as of starch/glucose and glutamine [33]. Since GDHs are known for their roles in arginine biosynthesis as well as $\mathrm{N}$ assimilation, therefore, we further searched for the DEGs enriched in arginine biosynthesis pathway. We found 20 DEGs enriched in arginine biosynthesis pathway, including both GHDs (Fig. 4a). Other DEGs included GSs, nitric oxide synthase (NOS), acetylornithine deacetylases (ADAs), N-acetyl-gamma-glutamyl-phosphate reductase (NaGGPR), aspartate aminotransferases (ASTs), and glutamate $\mathrm{N}$-acetyltransferase (GLGAT). The ADAs had expressions in MD-2 and TN21, while none was differentially expressed in BL vs. TN23.

Additionally, we found 12 antenna proteins (LHCBs, light-harvesting complex II chlorophyll a/b binding proteins), and 28 DEGs associated with photosynthesis pathway (Fig. 4a). The LHCBs showed variable expression patterns in different pineapple varieties. For example, all LHCBs had higher expressions in MD-2 as compared to BL. LHCB4s were mostly downregulated in pineapple varieties as compared to BL. All LHCBs were upregulated in TN17 as compared to BL. The genes annotated as Fd, were not differentially expressed in all variety comparisons; downregulated in $\mathrm{CN}, \mathrm{TN} 4$, and TN23, and upregulated in TN21. Similarly, F-type ATPases were only differentially expressed in BL vs. TN4 and BL vs. TN23; where BL had higher expressions. Major expression changes were noted in photosystem II oxygen-evolving enhancer proteins (PSBQs). PSBQ1 was only differentially expressed in BL vs. TN23 (downregulated in TN23). PSBQ2s and PSBQ3s showed both up/downregulation in the compared varieties to BL. One particular observation was the contrasting regulation of the PSBQ protein in TN23. When these proteins were upregulated in other varieties, TN23 showed downregulation and vice versa. This was also true for PSI subunit x, cytochrome c6, and Psb27 (Fig. 4a).

D-leaf transcriptome comparison of $\mathrm{CN}$ with other varieties Considering higher $\mathrm{P} \%$ in $\mathrm{CN}$ pineapple, we sought to compare its D-leaf transcriptome with the remaining six varieties. There were $5951,7768,2761,4383,3263$, and 5404 DEGs in $\mathrm{CN}$ vs. $\mathrm{MD}-2, \mathrm{CN}$ vs. $\mathrm{BL}, \mathrm{CN}$ vs. TN4, $\mathrm{CN}$ vs. TN17, CN vs. TN21, and CN vs. TN23, respectively (Supplementary Fig. 2a). The DEGs were significantly enriched in different pathways i.e., plant-pathogen interaction, starch and sucrose metabolism, flavonoid biosynthesis, phenylpropanoid biosynthesis, $\mathrm{ABC}$ transporters, and glutathione metabolism.

\section{Differential regulation of genes associated with P transport and metabolism}

Phosphorus plays vital roles in plants including energy transfer, photosynthesis, transformation of sugars and starches, and is a major component of nucleic acids, membrane lipids, and phosphorylated intermediates of energy metabolism [34-36]. We observed the differential expression of nine P transporters (Fig. 5). Of these, four were inorganic phosphate transporters (PHTs); only one (gene-LOC109707144) was upregulated in MD-2, $\mathrm{BL}$, TN4, and TN17 as compared to $\mathrm{CN}$, while three others were downregulated in other genotypes as compared to $\mathrm{CN}$. Remaining five $\mathrm{P}$ transporters were members of solute carrier family 25 and annotated as mitochondrial phosphate transporters (MPTs). Interestingly, these MPTs were only differentially regulated between $\mathrm{CN}$ vs. MD-2 and CN vs. BL. Apart from this we also found that 22 WRKY transcription factors (TFs); two WRKY2, six WRKY22, 11 WRKY33, one WRKY51-like, and one WRKY52, were differentially regulated between the CN and other genotypes. The expression of these WRKYs was higher in MD-2, BL, TN4, TN17, and TN23 as compared to $\mathrm{CN}$. Only, TN21 had higher expression of WRKYs (WRKY33s and WRKY52) as compared to CN. Suggesting that the P levels might be affected by changes in the WRKYs' expression $[37,38]$. We also checked if bHLH TFs, and MYB TFs were differentially regulated between these variety comparisons. Sixteen bHLH TFs and $60 \mathrm{MYB}$ TFs were differentially expressed in D-leaves of different varieties. Eight MYB TF were annotated as MYB-related TF LHY; all of these were downregulated in all varieties except TN23, where only one MYB-LHY was differentially expressed (upregulated). Other MYB TFs showed variable expression patterns. All differentially expressed bHLH TF in CN vs. MD-2 were upregulated in MD-2 as compared to CN. Only one bHLH TF was differentially expressed in TN4; the expression was reduced as compared to $\mathrm{CN}$, while others had variable expression in D-leaves of the tested varieties. These expression changes indicate that major players in Pi transport in D-leaf of pineapple are PHTs, MPTs, WRKYs, MYBs, and bHLHs [16, 17] (Fig. 5).

\section{D-leaf transcriptome comparison of MD-2 with other pineapple varieties}

Transcriptome comparison of MD-2 with the remaining six pineapple varieties revealed that there were 5951, $1695,4351,2876,5488$, and 4861 DEGs in MD-2 vs. CN, MD-2 vs. BL, MD-2 vs. TN4, MD-2 vs. TN17, MD-2 vs. TN21, and MD-2 vs. TN23, respectively. These DEGs 

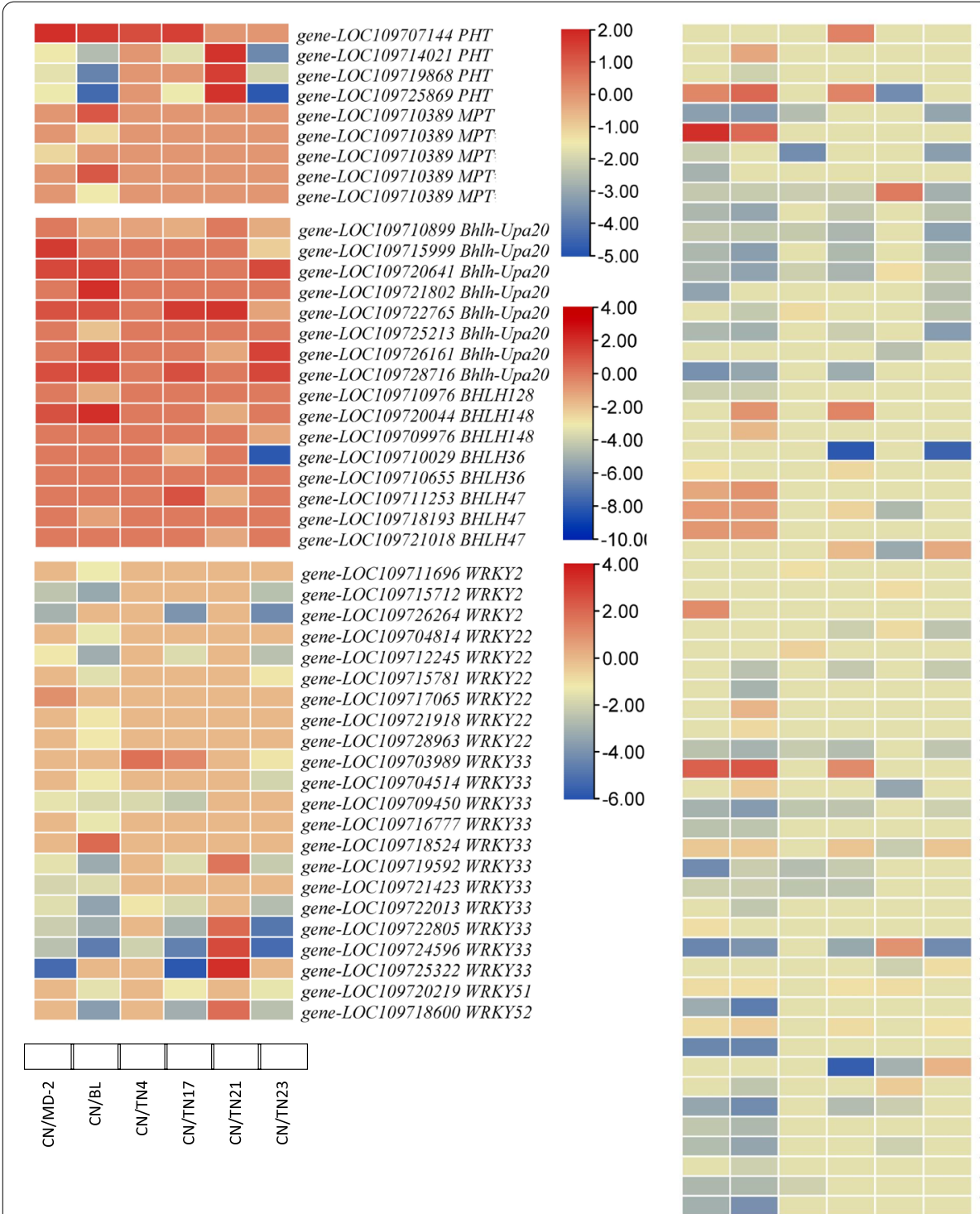

gene-LOC109703729 MYB gene-LOC109704273 MYB gene-LOC109704373 MYB gen-LOC $109704450 M Y B$ gene-LOC 109704756 MYB gene-LOC109704844 MYB gene-LOC109705368 MYB gene-LOC109706575 MYB gene-LOC 109706620 MYB gene-LOC109706835 MYB gene-LOC109707143 MYB gene-LOC 109707173 MYB gene-LOC $100708530 \mathrm{MY}$ gene-LOC 109005828 MY gene-LOC 109708828 MYB gene-LOC109709211 MYB gene-LOC109709688 MYB gene-LOC109712398 MYB gene-LOC109713839 MYB gene-LOC109714912 MYB gene-LOC109715073 MYB gene-LOC10971 gene-LOC 109715569 MYB gene- $L O C 109716587 M Y B$ gene- $L O C 109716607 M Y B$ gene-LOC109716915 MYB gene-LOC109716986 MYB gene-LOC109718059 MYB gene-LOC109718915 MYB gene-LOC109718969 MYB gene-LOC 109719663 MYB gene-LOC 109718653 MYPB gene-LOC 10719693 MYB gene-LOC109720256 MYB gene-LOC109720287 MYB gene-LOC109720988 MYB gene-LOC109721215 MYB gene-LOC109722005 MYB gene-LOC109722617 MYB gene-LOC109722735 MYB gene-LOC109723346 MYB gene-LOC109723346 MYB gene-LOC 109723797 MYB gene-LOC109723847 MYB gene-LOC109724819 MYB gene-LOC109725533 MYB gene-LOC109725589 MYB gene-LOC109725762 MYB gene-LOC109726220 MYB gene-LOC109728215 MYYB gene-LOC 109728215 MYB gene-LOC 109728373 MYB gene-LOC109728404 MYB gene-LOC109728929 MYB gene-LOC109710073 MYB gene-LOC109717436 MYB gene-LOC 109718315 myb W gene-LOC109704376 MYB-LHY gene-LOC109704998 MYB-LHY gene-LOC109707582 MYB-LHY gene-LOC109707632 MYB-LHY gene-LOC109714145 MYB-LHY gene-LOC109714145 MYB-LHY
gene-LOC109727385 MYB-LHY gene-LOC109727721 MYB-LHY gene-LOC109728581 MYB-LHY

Fig. 5 Heatmaps of DEGs related to phosphate transport in D-leaves of six pineapple varieties as compared to CN. Golden pineapple (MD-2), Caine (CN), Bali (BL), Tainong no. 4 (TN4), Tainong no. 17 (TN17), Tainong no. 21 (TN21), and Tainong no. 23 (TN23)

were significantly enriched in plant-pathogen interaction, $\mathrm{ABC}$ transporters, starch and sucrose metabolism, glutathione metabolism, anthocyanin biosynthesis, and flavonoid biosynthesis pathways.

\section{Differential regulation of genes associated with $\mathrm{K}$ transport and metabolism}

Upon arrival in the roots, $\mathrm{K}^{+}$is either stored in vacuoles locally or transported to the aerial parts where it is accumulated. To this regard, we found the differential regulation of four $\mathrm{H}^{+}$transporting ATPases. Three were differentially regulated in $\mathrm{MD}-2$ vs. $\mathrm{CN}$, where their expression was lower in $\mathrm{CN}$. None was regulated between
MD-2 vs. BL, TN17, and TN23. One was expressed in TN4 (upregulated), while two were expressed variedly in TN21 (Fig. 6). Apart from these, we also found the differential expression of F-type $\mathrm{H}^{+}$transporting ATPases between the variety comparisons. Both types of $\mathrm{H}^{+}$transporting ATPases play roles in $\mathrm{K}^{+}$transport in plants [39]. Seven V-type $\mathrm{H}^{+}$-transporting ATPases (two $16 \mathrm{kDa}$ proteolipid subunits, subunits $\mathrm{c}, \mathrm{d}, \mathrm{e}, \mathrm{f}$, and $\mathrm{g}$ ) were differentially expressed in pineapple D-leaves. One $16 \mathrm{kDa}$ proteolipid subunit was upregulated in $\mathrm{CN}$ and $\mathrm{TN} 4$, while the other was downregulated in $\mathrm{CN}$, TN4, and TN23. Subunit $C$ was upregulated in TN21, subunit $\mathrm{d}$ was upregulated in TN23, subunit e was upregulated 


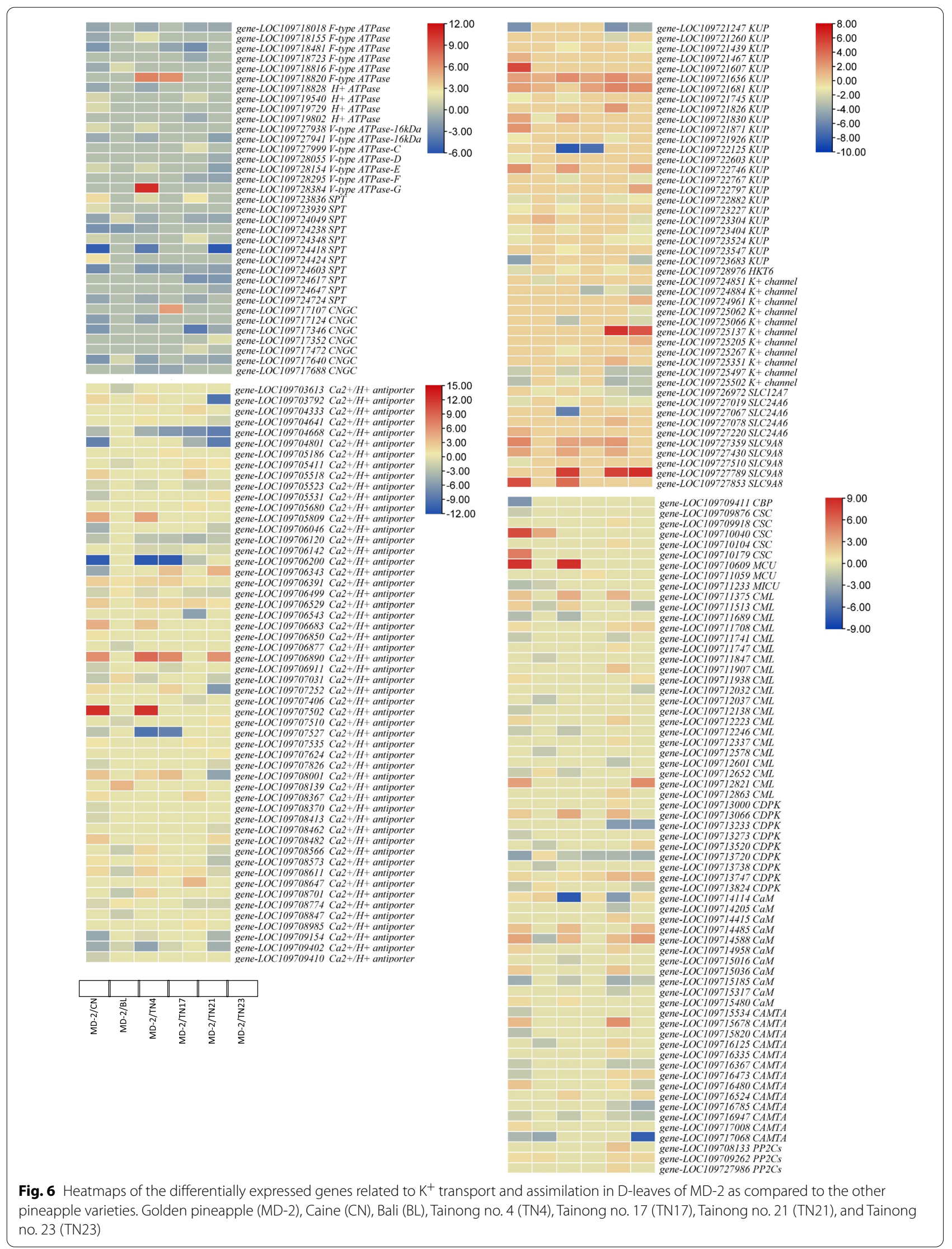




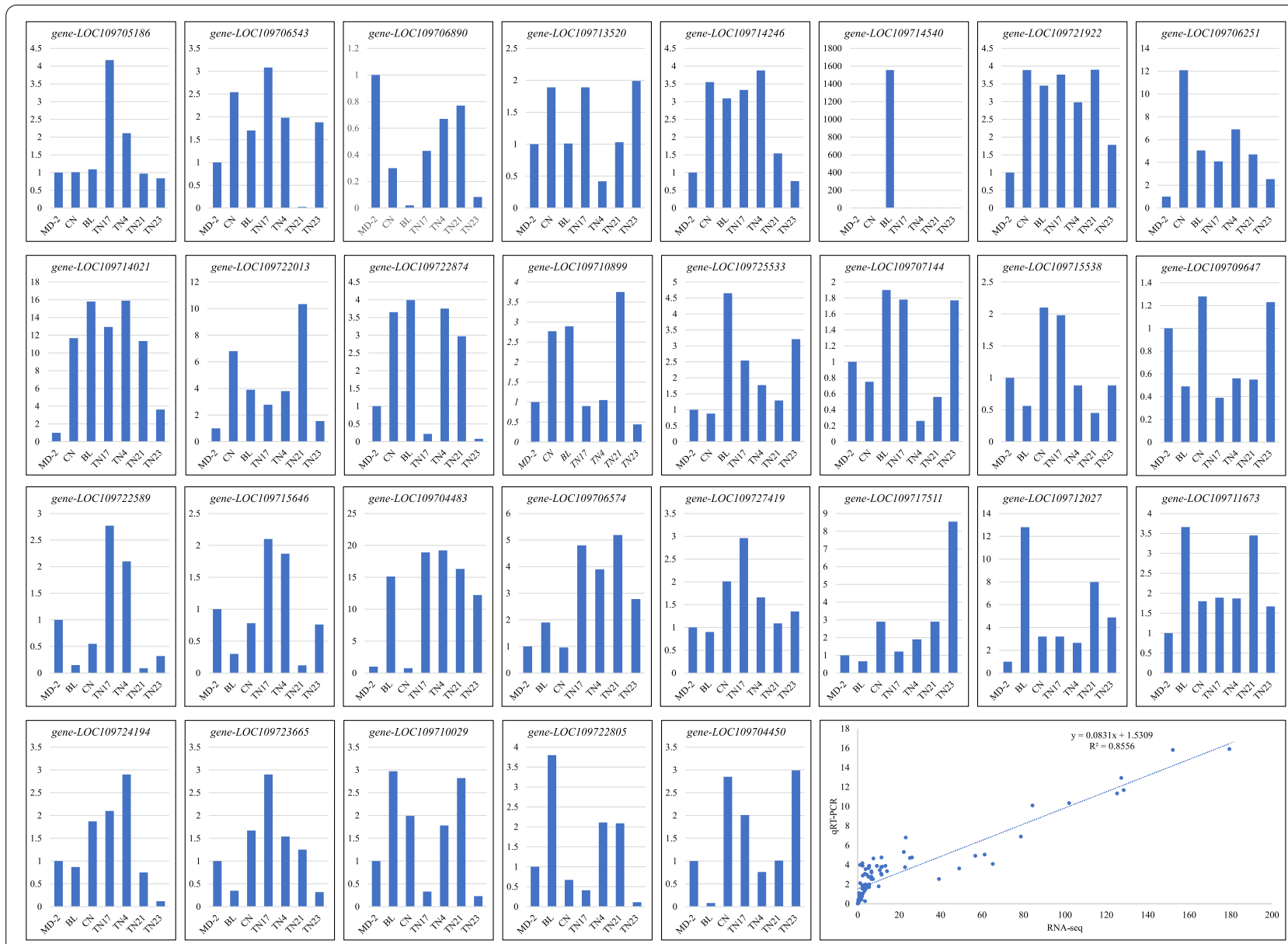

Fig. 7 Expression analysis of selected genes in D-leaves of seven pineapple varieties. X-axes represent the varieties and $Y$-axes represent the relative gene expression. The last panel shows correlation between qRT-PCR expression data and RNA-Seq data of the selected genes. Golden pineapple (MD-2), Caine (CN), Bali (BL), Tainong no. 4 (TN4), Tainong no. 17 (TN17), Tainong no. 21 (TN21), and Tainong no. 23 (TN23). X-axis shows varieties and Y-axis shows relative gene expression

in $\mathrm{CN}$, TN4, while downregulated in TN23, subunit $\mathrm{F}$ was downregulated in TN21 and TN23, and subunit G was upregulated in TN4, respectively. These expression changes along with the regulation of 11 sugar: $\mathrm{H}^{+}$ symporters (SPTs), and members of solute carrier families 12, 24, and 9 (SLCs) is indicative of differential K\% content within the D-leaves of the studied pineapple varieties (Fig. 6). Major observation was the differential expression of 24 KUP system potassium uptake proteins (KUPs). Seven and eight KUPs were up- and downregulated in $\mathrm{CN}$ as compared to MD-2, respectively. In MD-2 vs. BL, MD-2 vs. TN4, MD-2 vs. TN17, MD-2 vs. TN21, MD-2 vs. TN23 there were 4, 11, 3, 7, and 11 differentially regulated KUPs. We observed that the expression of some KUPs was increased while in MD-2 while others' expression was decreased. We also found differential regulation of K-channels in D-leaves of the compared varieties. Maximum number of K-channels were differentially expressed between MD-2 and TN23 (eight) followed by MD-2 vs. TN21 (five). Other variety comparisons showed the expression of four or less K-channels (Fig. 6). Interestingly, we found that MD-2 K-channels had higher expression as compared to all varieties except three and two genes in TN21 and TN23, respectively. Considering the higher expression of these channels as well as the differential expression of seven cyclic nucleotide gated channels (CNGCs), it could be suggested a key player in higher $\mathrm{K} \%$ contents in MD-2. We also found one probable cation transporter HKT6, which was downregulated in $\mathrm{CN}$, TN4, and TN21 as compared to MD-2. Apart from transporters, we also looked for genes that affect the expression of K-transporters and related genes. Interestingly, a large number of $\mathrm{Ca}^{2+}$ exchange, transport, and signaling related genes were differentially expressed in D-leaves of studied pineapple varieties. Forty-nine $\mathrm{Ca}^{2+} /$ $\mathrm{H}^{+}$antiporters, five $\mathrm{Ca}^{2+}$ transporting ATPases, a $\mathrm{Ca}^{2+}$ 


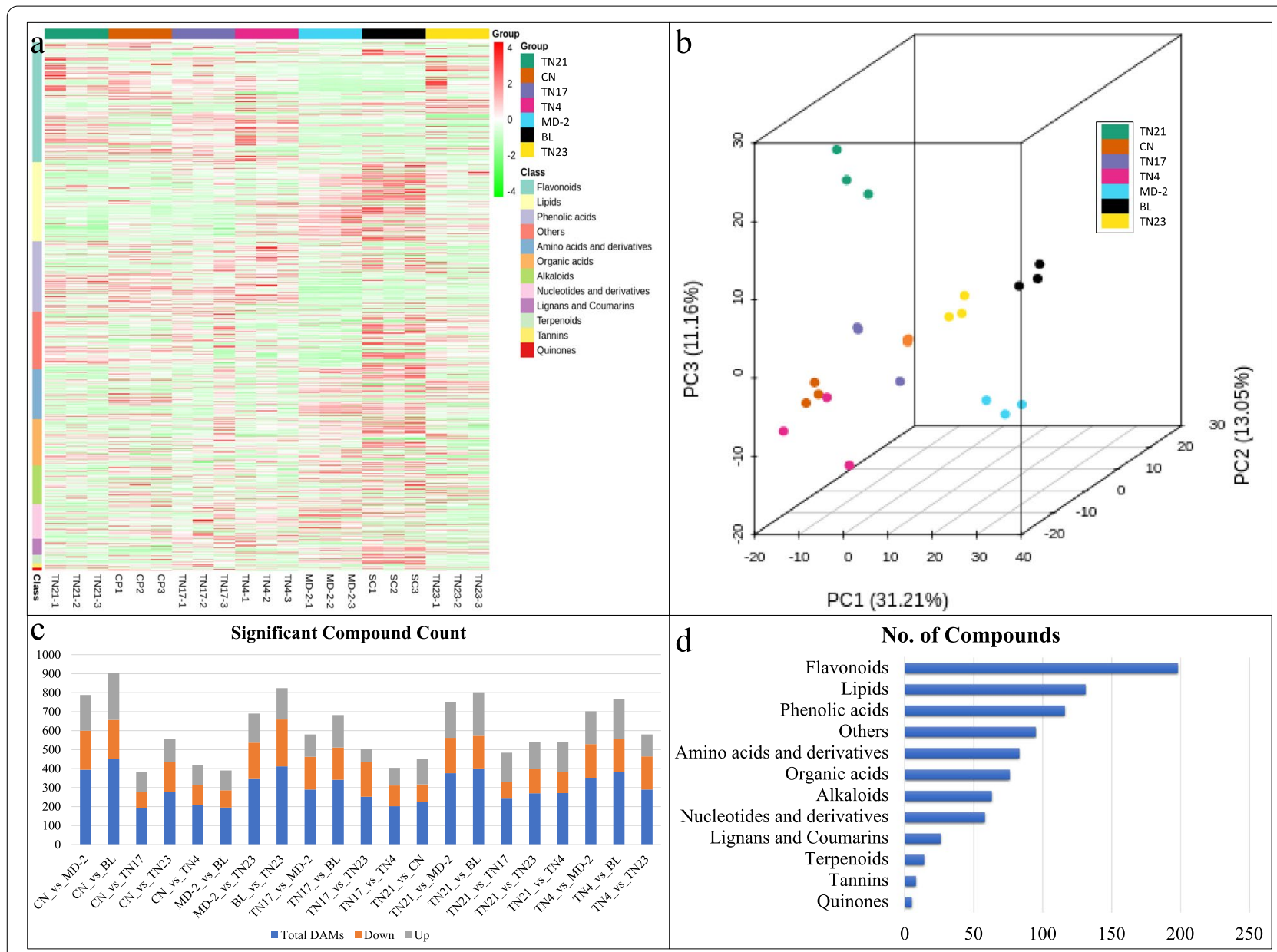

Fig. 8 Metabolite profile of D-leaves of pineapple varieties. a Heatmap showing the intensities of the detected compounds and their classification, b principal component analysis, $\mathbf{c}$ significant compound count between the variety comparisons, and $\mathbf{d}$ number of detected compounds in each class. DAMs: Differentially accumulated metabolites. Golden pineapple (MD-2), Caine (CN), Bali (BL), Tainong no. 4 (TN4), Tainong no. 17 (TN17), Tainong no. 21 (TN21), and Tainong no. 23 (TN23)

binding protein 39,5 calcium permeable stress-gated cation channels, $2 \mathrm{Ca}^{2+}$ uniporter proteins, $1 \mathrm{Ca}^{2+}$ uptake protein 1, 20 calcium-binding protein CMLs (CMLs), 9 calcium-dependent protein kinases (CDPKs), 11 calmodulins (CaMs), three protein phosphatase 2Cs (PP2Cs) and 13 calmodulin-binding transcription activators (CAMTAs) (Fig. 6).

\section{Quantitative Real-Time PCR analysis}

We validated the expression of 29 pineapple genes of interest (Fig. 7). The Actin gene was used as an internal control. Based on the correlation $\left(R^{2}=0.8556\right)$ between qRT-PCR data and RNA-seq data of the genes, we found that the expression of the selected genes was in accordance with the RNA-seq data (Fig. 7). These analyses validate the transcriptome sequencing results and confirm their reliability.
Apart from the validation of the reliability of the RNA sequencing data, the genes also show that the studied varieties express these genes differentially as discussed in the above sections.

\section{Metabolite profiles of $D$-leaves of pineapple varieties}

UPLC-MS/MS detection platform, a self-built database, and the multivariate statistical analyses of 21 samples belonging to D-leaves of seven pineapple varieties resulted in the detection of 873 metabolites (Supplementary Table 3; Fig. 8a). The detected metabolites were broadly classified as flavonoids, lipids, phenolic acids, amino acids and derivatives, alkaloids, nucleotides and derivatives, lignans and coumarins, terpenoids, tannins, and quinones (Fig. 8a). The PCA analysis grouped the replicates according to the varieties. TN23, MD-2, and BL showed variability from other varieties, while the rest of varieties tended to group (Fig. 8b). The accumulated 

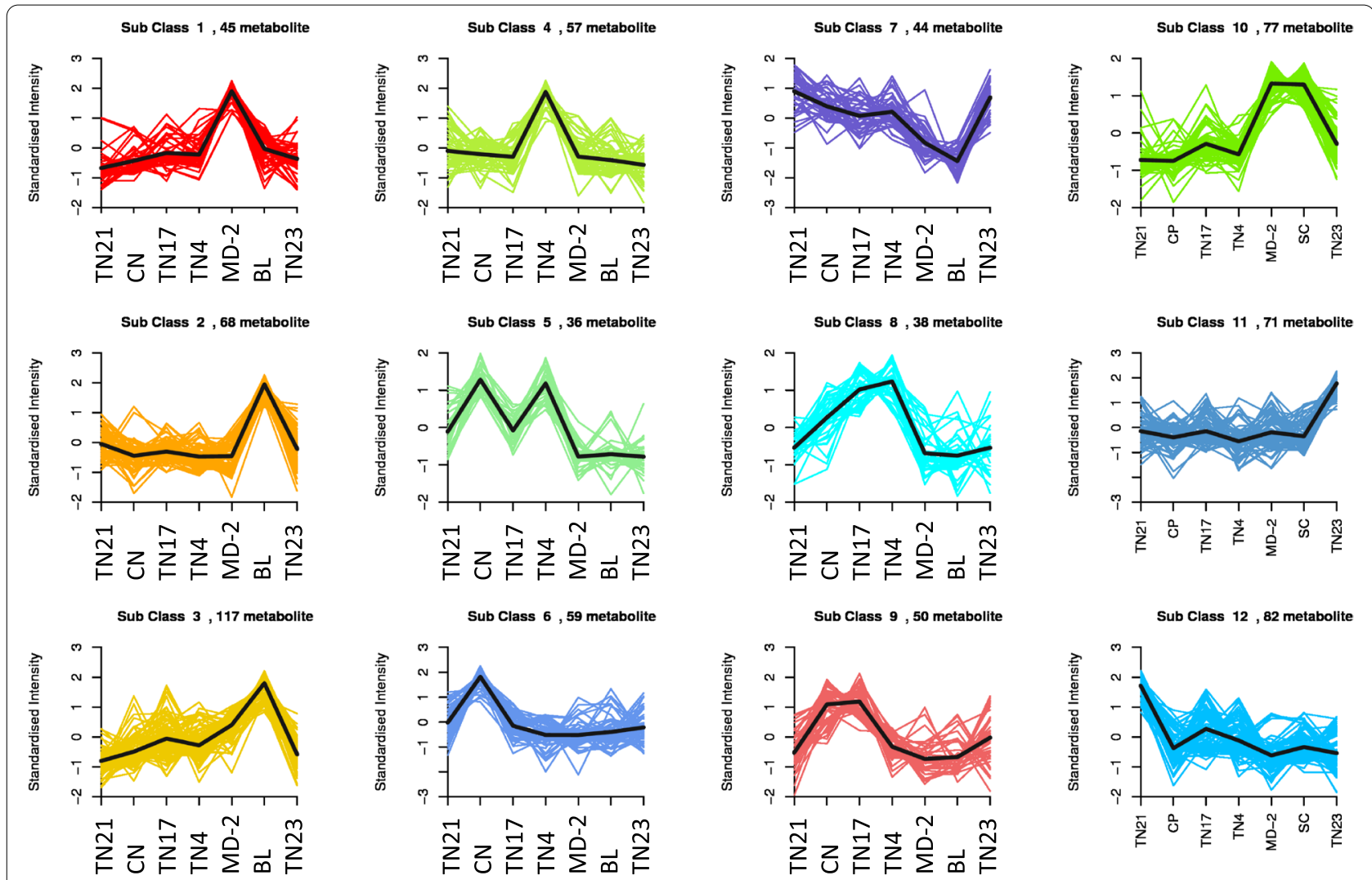

Fig. 9 K-means cluster analysis of the detected metabolites in D-leaves of seven pineapple varieties. Golden pineapple (MD-2), Caine (CN), Bali (BL), Tainong no. 4 (TN4), Tainong no. 17 (TN17), Tainong no. 21 (TN21), and Tainong no. 23 (TN23)

metabolites were screened based on fold change $\geq 2$ and $\leq 0.5$ and VIP $\geq 1$; the differentially accumulated metabolites (DAMs) in the D-leaves of the seven pineapple varieties are shown in Fig. 8c. The D-leaves of pineapple varieties were rich in flavonoids (198 compounds), lipids (131 compounds), and phenolic acids (116 compounds) (Fig. 8d).

\section{Differentially accumulated metabolites in D-leaves of pineapple varieties}

In order to understand the accumulation of metabolites in pineapple varieties having higher $\mathrm{N}, \mathrm{P}$, and $\mathrm{K} \%$ contents, we used the K-means cluster analysis results. As discussed above, the BL pineapple had significantly higher N\% contents, therefore, we looked into the subclass of compounds that had higher accumulation in BL as compared to other varieties. Three subclasses of compounds i.e., subclass 2 (68 metabolites), 3 (117 metabolites), and 10 (77 metabolites) showed higher standardized intensities of compounds as compared to other varieties (Fig. 9). The metabolites in subclass 2 were mainly saccharides and alcohols, and organic acids. Subclass 3 had a higher number of metabolites classified as lipids, amino acids and derivatives, flavonoids, organic acids, and phenolic acids. Similarly, subclass 10 had also higher number of metabolites classified as lipids, amino acids and derivatives, lignans and coumarins, and flavonoids (Supplementary Table 4). The top-10 most accumulated metabolites in BL were Methylmalonic acid*, succinic acid, arachidic acid, L-valine, lysoPE 18:1, D-glucose, pipecolic acid, D-fructose, L-valyl-L-leucine, and 4-Nitrophenol. Mainly, these metabolites were enriched in starch and sucrose metabolism, biosynthesis of amino acids, and fatty acid biosynthesis and related pathways. Two metabolites i.e., L-glutamine and L-glutamic acid were enriched in nitrogen metabolism pathway, however, their content was highest in MD-2 and TN4, respectively.

Since CN had higher P\% contents, therefore, we looked for compounds with higher standardized intensities (subclass 5 (36 metabolites), 6 (59 metabolites), and 9 (50 metabolites)) in this pineapple variety as compared to others (Fig. 9). The metabolites included in subclass 5 were classified as phenolic acids and flavonoids, while those included in subclass 6 were classified as flavonoids, amino acids and derivatives, alkaloids, phenolic 
acids, and organic acids. Similarly, subclass 9 had higher number of flavonoids and organic acids. Top-10 most accumulated metabolites in $\mathrm{CN}$ were arachidic acid, chlorogenic acid, 2,3-dihydroxy-3-methylbutanoid acid, L-valine, L-ascorbic acid, neochlorogenic acid, cryptochlorogenic acid, 5,4'-dihydroxy-3,6,7,3'-tetramethoxyflavone-4'-O-glucoside, N',N"-Diferuloylspermidine, and aurantio-obtusin-6-O-glucoside. These top-accumulated metabolites were enriched in phenylpropanoid biosynthesis, flavonoid biosynthesis, secondary metabolite biosynthesis, and valine and isoleucine biosynthesis pathways (Supplementary Tables 3, 4).

As MD-2 had higher K\% contents, it had higher standardized intensities of subclass 1 and 10 having 45 and 77 metabolites, respectively (Fig. 9). The metabolites included in subclass 1 were classified as nucleotides and derivatives, lipids, and amino acids, and derivatives while those included in subclass 10 were classified as lipids, amino acids and derivatives, lignans and coumarins, and flavonoids. Top-10 metabolites accumulated in MD-2 were arachidic acid, guanosine, methylmalonic acid, succinic acid, 2,3-dihydroxyl-3-methylbutanoic acid, L-valyl-L-Leucine, L-valine, lysoPE 18:1, L-norleucine, and L-gycyl-L-phenylalanine. These metabolites were mostly enriched in pathways related to amino acid biosynthesis, citrate cycle, $\mathrm{ABC}$ transporters, and biosynthesis of secondary metabolites (Supplementary Tables 3, 4).

\section{Discussion}

Pineapple being the third most important tropical fruit in China needs attention regarding improvements in nutrient management and finding candidate genes/pathways to be engineered in this regard. In different crop plants, the leaf color indicates the nutrient content level and farmers manage to supply the nutrients either by spraying the above ground parts of by adding fertilizers to the soil [29-31]. We have observed that the leaf colors of the pineapple varieties differ from each other (Fig. 1a) and hence, designing a leaf-colour chart to help the farmers is quite difficult. Alternate strategy would be the understanding of the key regulatory genes and pathways and manipulating them through gene modification and engineering techniques. An early understanding for such a task is to determine the key transcriptomic and metabolomic changes. Through this study, we have provided the transcriptomic and metabolomic signatures in the D-leaves of seven famous pineapple varieties cultivated in China.

\section{Nitrogen transport, assimilation, and metabolism in the D-leaves of pineapple}

Early researches had determined that variation in leaf NPK contents leads to changes in overall plant health, yield, and fruit quality $[3,9]$. The mechanisms behind the variable NPK contents could be a possible reason since it is known that higher allocation of $\mathrm{N}$ in leaves maximizes $\mathrm{C}$ gain in leaf by increasing photosynthesis $[40,41]$. Our observations that 30 genes related to nitrogen assimilation were differentially regulated indicates that the studied varieties differently utilize their $\mathrm{N}$ transport and assimilation to manage their D-leaf $\mathrm{N}$ contents. Particularly, the differential expression of $\mathrm{N}$-transporters suggested that $\mathrm{N}$ arrives in $\mathrm{D}$-leaves of pineapple varieties differently (Fig. 4a). Here it is important to discuss that the AMTs and NRTs are located in roots to absorb nitrogen from soil in form of ammonium and nitrate, however, the expression of NRTs (e.g., NRT1.2, NRT1.4, NRT1.6, and NRT2.7) [6, 10] and AMTs (TeAMT2;3a, LjAMT1;1, BnAMT1;2, LeAMT1;2, NtAMT1;3, PtrAMT2;2) has also been confirmed in leaves of different plants [42,43 and references therein]. The arrived $\mathrm{N}$ in pineapple D-leaves was being reduced to ammonium as evident from the differential expression of [44]. Further, the $\mathrm{N}$ assimilation in the D-leaves of the pineapple varieties differed as we noted the differential expression of GSs. It is important to note that this step of $\mathrm{N}$ assimilation/metabolism was not differentially regulated between BL (variety having significantly higher N\% contents) and MD-2 and TN17. Since, our results showed the differential regulation of $G D H 1$ and $G D H 2$ in the D-leaves of the seven pineapple varieties, therefore, it is possible that differences in N\% content could be their varied expressions [33]. Because, both GDHs had contrasting expressions, thus, these two genes are prime targets for characterization in pineapple. GSs along with GDH assimilate nitrogen into amino acids $[45,46]$. Enrichment of DEGs as well as DAMs in amino acid biosynthesis related pathways (Fig. 7d) is indicating that these enzymes are primarily playing roles in $\mathrm{N}$ assimilation (owing to their presence in the upstream of biosynthesis pathways of multiple amino acids e.g., arginine biosynthesis (Fig. 4a), leucine and isoleucine biosynthesis (Supplementary Tables 3 and 4). The detection of a higher number of amino acids and derivatives in BL strongly correlates with the higher N\% contents. Not only GS but also no differential expression of GOGAT in BL vs. TN17 proposes that the variation of $\mathrm{N}$ content in the D-leaves of these two varieties is possibly being regulated at some other step.

Since the NR, NiR, and GOGAT have different reducing power requirements (it could be NADH or ferredoxin, Fd), therefore, these should be provided by the 
photosynthesis or related pathways. Additionally, GS needs ATP and amino acid biosynthesis (organic N) needs $\mathrm{C}$ skeletons, which are received as products of photosynthesis. Therefore, the varied expression of the DEGs enriched in photosynthesis-antenna proteins pathways (LHCBs) suggests that different levels of light energy are being captured, which is affecting the delivery of excitation energy to the photosynthesis $[6,47]$. Apart from the antenna proteins, the observation that $\mathrm{Fd}$ genes were downregulated in $\mathrm{CN}$, TN4, and TN23 and upregulated in TN21 as compared to BL (Fig. 4a) suggests that the reducing power requirements for NR, NiR, and GOGAT are being regulated differently in the studied pineapple varieties (at least in D-leaves). It is known that reducing power is essential for nitrate and nitrite reduction and is mainly supplied by the photosynthetic electron transfer chain; the requisite $\mathrm{Fd}$ is generated here [48]. The expression changes of other proteins i.e., PSBQs further suggest that the studied pineapple varieties exhibit differential regulation of photosystem II. Thus, the $\mathrm{N} \%$ content differences in these varieties are being regulated from transport to assimilation. Furthermore, the role of affiliated pathways is not to be neglected. For example, arginine has the highest $\mathrm{N}$ to $\mathrm{C}$ ratio $(40-50 \%$ of the total $\mathrm{N}$ reserves) [49], therefore the regulation of arginine biosynthesis pathway related genes i.e., GSs, GDHs, NOS, ADAs, NaGGPR, ASTs, and GLGATs in D-leaves of the studied pineapple varieties is of interest (Fig. 4a). The increased expression of ASTs in MD-2 as compared to $\mathrm{BL}$ is interesting. It could suggest that relatively higher $\mathrm{N}$ is MD-2 is being directed to arginine biosynthesis as compared to BL. We say this because of the known role of AST in arginine biosynthesis pathway [50]. Taken together, $\mathrm{N}$ the studied varieties differ for their D-leaf N\% contents and the transcriptome and metabolome changes suggest the $\mathrm{N}$ transport, assimilation, metabolism, and downstream pathways i.e., biosynthesis of amino acids is being regulated at different steps. Furthermore, the photosynthesis and antenna proteins also take part in $\mathrm{N}$ assimilation.

\section{Pi transport and metabolism in D-leaves of pineapple}

Phosphorus is a crucial macronutrient because it is a structural constituent nucleic acids, phospholipids, and energy related molecules in plants i.e., ATP. It is also integral to photosynthesis and respiration [51]. Many studies revealed the role of Pi in pineapple plant growth, development, yield, and fruit quality [3, 52-54]. Phosphorus is transported in the plant tissues through PHTs. D-leaves of the studied pineapple varieties have two different types of P transporters i.e., PHTs and MPTs, which showed variable expression patterns in the studied pineapple varieties. Pi transport is being controlled differentially. PHTs acquire and distribute $\mathrm{Pi}$ among tissues and also help plant to manage Pi homeostasis [51]. On the other hand, the MPTs work to control the Pi exchange between cytoplasm and mitochondria [55]. These expression changes suggest that there are two prime targets for Pi homeostasis in pineapple D-leaves. Since, the MPTs were only differentially expressed between $\mathrm{CN}$ vs. MD-2 as well as $\mathrm{CN}$ vs. $\mathrm{BL}$, thus, these three pineapple varieties might be using both types of transporters for Pi homeostasis. In particular to this observation, these three varieties should be explored in future studies. Earlier studies have indicated the involvement of multiple TFs in Pi transport and metabolism in plants. For example, WRKY42, WRKY45, and WRKY6 (along with other unknown TFs) are known for transcriptional regulation of PHTs [56]. Similarly, it is known that MYB TFs regulate the expression of phosphate transport related genes $[57,58]$. Our observations that the D-leaves of pineapple varieties differed in the expression of a large number of WRKY, MYB, and bHLH TFs proposes that the pineapple PHTs are being transcriptionally regulated by these TFs $[16,17]$. The roles of individual TFs in Pi transport in pineapple e.g., WRKY2, WRKY22, WRKY33, WRKY51-like, and WRKY52 needs specific characterization studies.

The metabolite enrichment in the flavonoid biosynthesis, secondary metabolite biosynthesis, valine and isoleucine biosynthesis is in accordance with the earlier reports that changes in Pi concentrations in leaves can affect the amino acid and flavonoid biosynthesis in tea plants [59]. Earlier studies also revealed that the N, P, and K contents in leaves are associated with the valine contents [60]. This is in line with our observations both in case of variety comparisons based on significantly higher N\% (BL) and P\% (CN) as discussed above. Taken together, it could be proposed that the studied pineapple varieties differ in their D-leaf P\% content due to differential expression and regulation of Pi transport and associated pathways.

\section{$\mathrm{K}^{+}$transport and metabolism in D-leaves of pineapple}

$\mathrm{K}^{+}$is transported in plants with the help of low affinity and high affinity transporters. The KUPs are low affinity $\mathrm{K}^{+}$transporters and uptake $\mathrm{K}^{+}$into the cell when $\mathrm{pH}$ is low [61,62]. The differential regulation of a large number of KUPs in D-leaves of the studied pineapple varieties emphasize that these varieties use KUPs for maintaining the cellular $\mathrm{K}^{+}$levels. Since, the $\mathrm{K}^{+}$influx is always accompanied by decrease in $\mathrm{H}^{+}$efflux [63], thus, the differential regulation of $\mathrm{H}^{+}$-ATPases, F-type $\mathrm{H}^{+}$-ATPases, and $\mathrm{V}$-type $\mathrm{H}^{+}$-ATPases is understandable (Fig. 6). Since $\mathrm{K}^{+}$mainly accumulates in vacuole due to $\mathrm{pH}$ gradient [15], and therefore, the expression of genes associated with vacuolar $\mathrm{pH}$ gradient development and $\mathrm{K}^{+}$accumulation is an indication of $\mathrm{K}^{+}$levels in leaves. While KUPs 
allow the transport of $\mathrm{K}^{+}$into the cell, the $\mathrm{K}^{+}$channels (SKOR-like, AKT, KOR, KAT, and TPC) help plants to modulate the $\mathrm{K}^{+}$levels [64] e.g., the expression of SKOR is modulated by the external $\mathrm{K}^{+}$levels. The differential regulation of these $\mathrm{K}^{+}$channels in the $\mathrm{D}$-leaves of the studied pineapple varieties indicated their essential roles in $\mathrm{K}^{+}$homeostasis. Additionally, the CNGC have also the potential to transport $\mathrm{K}^{+}$[65], thus it is obvious from their expression that they are playing similar roles in pineapple D-leaves. The differential expression of HKT6 in $\mathrm{CN}, \mathrm{TN} 4, \mathrm{TN} 21$, and MD4 suggests long-distance $\mathrm{K}^{+}$transport in pineapple leaves. The HKT gene family members have been characterized for their involvement in $\mathrm{K}^{+} / \mathrm{Na}^{+}$regulation. The HKTs apart from transport, are also involved in mediating salt tolerance in different plants. The presence and the expression of HKT6 should be specifically studied in pineapple under salt stress conditions [66]. Since, $\mathrm{K}^{+}$transport and accumulation are also associated with $\mathrm{Ca}^{2+}$ signaling therefore, the changes in the expression of related genes are important observation [67]. Particularly, it is noteworthy that a large number of $\mathrm{Ca}^{2+} / \mathrm{H}^{+}$antiporters were differentially expressed in the $\mathrm{D}$-leaves of pineapple varieties, indicating potential roles in $\mathrm{K}^{+}$homeostasis [68]. The large number of $\mathrm{Ca}^{2+}$ signaling related proteins were expressed between the pineapple varieties is in accordance with the recent findings. Particularly, it is known that GORK are phosphorylated by CDPK genes [69]. Though we didn't observe the differential regulation of GORKs, the differential regulation of nine CDPKs implies that in pineapple, they might be interacting with other $\mathrm{K}^{+}$channels or probably GORKs. We say this because we also noted the varied expression of PP2Cs (Fig. 6) and PP2CAs (Supplementary Table 2). PP2CA in Arabidopsis is known to interact physically with GORK and inhibits its current [70]. Thus, the CKPK and PP2CAs together regulate GORK.

Table 1 List of Primers used in the qRT-PCR analysis

\begin{tabular}{|c|c|c|}
\hline Gene ID & Primer forward sequence $\left(5^{\prime}-3^{\prime}\right)$ & Primer reverse sequence $\left(5^{\prime}-3^{\prime}\right)$ \\
\hline Actin & CGAAATACCATTGAGC & TCCACTGTATTTCTCGCC \\
\hline gene-LOC109705186 & AGGAGAAAAGGAGTACC & AGCCACTATACTGCAT \\
\hline gene-LOC109706543 & ACTACGCCTATTGAGACCG & CGAGAAGGATTTGACCTA \\
\hline gene-LOC109706890 & CGAGTGCTAACATTTCTT & TTGCCCCATAAAACCTC \\
\hline gene-LOC109713520 & GAAAGGAAGAAACGCTT & AATGAGGCCAAAACACAAT \\
\hline gene-LOC109714246 & TTCGTTGAGAAACCTACG & TCAATCACTTCCATCTCA \\
\hline gene-LOC109714540 & GATTGAGAGGAGGCAAG & TCTATCACTTCCСТCTTTT \\
\hline gene-LOC109721922 & GTGATCTACGTGCGAC & TGGATATACCCCATCTAT \\
\hline gene-LOC109706251 & GAACCACTTACGCCTTAC & TTTTCCTGTTTGGTATC \\
\hline gene-LOC109722874 & AATTGAGCCGTATGAGGTA & TTACGGTGCCTACCAAT \\
\hline gene-LOC109710899 & TGGACAAAGACACAATC & TTGAATTTCGATCTTTCC \\
\hline gene-LOC109725533 & CATGCAAAAACTGCCAAA & AGCACTCAAAGGTTCAAT \\
\hline gene-LOC109707144 & TGGTTCATACATCCTTGG & TAATTGATGCCTAAATTT \\
\hline gene-LOC109714021 & CTGCCCAATATTTGAGTT & АССТССТСССТАСАСАA \\
\hline gene-LOC109722013 & AACCTCTTTCGACGA & GATTTTGACACCCCTGA \\
\hline gene-LOC109715538 & TAACTCGTCCCGAAAACACC & TCGATGAATGGCAACGATAA \\
\hline gene-LOC109709647 & GATTACCACGTACAATCGGA & TAGAGCCATGGACCGCTAAC \\
\hline gene-LOC109717511 & CAAAGCCTTTACGCAAGGAG & TAATTGGCCCCTTCAACAAG \\
\hline gene-LOC109712027 & GGCTGAAGGGAGGAAA & ATCGTGGTCGTTGTCG \\
\hline gene-LOC109711673 & TGGAACCTGCTACATTGCTG & CATTTTGCCAGGTTCAAGGT \\
\hline gene-LOC109722589 & GGTGGACAGCCAGATT & CATGTCTGGCAACAAAATCG \\
\hline gene-LOC109715646 & GGATGGTCCTTGTCAAACTCA & TTGGCCATGTTGTCACTTGT \\
\hline gene-LOC109704483 & GATAATGGCGAATGGCTGAT & TCATCCCTGGAATGTCGAGT \\
\hline gene-LOC109706574 & GTAAGCAAGTGGCGCATACA & AAGACGGGTGGAGAAA \\
\hline gene-LOC109727419 & GAAGCTCAGCAGCATCAGAA & TGGGTTCTATGGCAAAGGAT \\
\hline gene-LOC109724194 & ACAGCGTTCTGAAAGCAACC & AGCCAGTGGATCCATTTCAC \\
\hline gene-LOC109723665 & CACTCACCCAGAATGGCTTT & TCGGTGGACCTTATTG \\
\hline gene-LOC109710029 & TCTATGACTTGGAGGAACA & CTGTCGGACGAGGATT \\
\hline gene-LOC109722805 & AGTACGGCAAGGGACACATC & ACGTGAGCAAACCCCTTTTT \\
\hline gene-LOC109704450 & TGCTGGAACTACTGACG & GCCCAAGCTTTAATGCCATA \\
\hline
\end{tabular}


A further characterization of this type of $\mathrm{K}^{+}$regulation in pineapple would reveal the possible causes of no GORK differential expression. Other than these, studies have reported evidences that low $\mathrm{K}^{+}$signaling is regulated by $\mathrm{Ca}^{2+}$-dependent pathway involving integrin-linked kinase (ILK), HAK5, and CMLs. Our findings in transcriptomic analysis showed the differential expression of CMLs (Fig. 6) and ILKs (Supplementary Table 2) suggesting that $\mathrm{K}^{+}$transport in pineapple $\mathrm{D}$-leaves is being $\mathrm{Ca}^{2+}$-dependent. From the metabolite perspective, our results that highly accumulated DAMs were enriched in citrate cycle are relevant to earlier reports that changes in $\mathrm{K}^{+}$levels cause the differential accumulation of metabolites e.g., citrate [71]. Additionally, the increased accumulation of lipids supports earlier results that $\mathrm{K}^{+}$content variation in plants affect lipid metabolism [72]. Taken together, it can be stated that the studied pineapple varieties have different $\mathrm{K} \%$ contents in their D-leaves and its transport and homeostasis are being regulated by known $\mathrm{K}^{+}$transporters and channels under the influence of $\mathrm{Ca}^{2+}$ signaling.

\section{Methods}

\section{Plant Materials and growth conditions}

Seven pineapple varieties i.e., Golden pineapple (MD2), Bali (Comte de Paris, $\mathrm{BL}$ ), Caine ( $\mathrm{CN}$, also known as Smooth Cayene), Tainong 17 (T17), Tainong 21 (T21), Tainong 4 (T4), Tainong 23 (T23) were obtained from Key Laboratory of Tropical Fruit Tree Biology, Ministry of Agriculture, The South Subtropical Crops Research Institute of Chinese Academy of Tropical Agricultural Sciences. No permissions are necessary to use such samples. The formal identification of the samples was conducted by Prof Jing Chen and no voucher specimens have been deposited. The plant materials were planted in Xuwen QuJie Town, Zhanjiang, Guangdong Province in November 2019. The soil was composed of laterite developed from basalt. Three well-grown pineapple plants (11 months old) of each genotype were randomly chosen for the leaf harvesting (October 2020). Three biological replicates were chosen from each variety. $5-10 \mathrm{~cm}$ long pineapple D- leaf fragments (fresh weight about 20-30 g) were collected. The fragments were cut from the middle of pineapple D-leaf using scissors. The leaves were further cut into smaller pieces, mixed well, and placed in a $15 \mathrm{ml}$ centrifugation tube. Centrifugal tubes were stored in a plastic foam container having liquid nitrogen. The samples were then taken back to the laboratory and stored in a -80 cryogenic chamber for the determination of N, P, and $\mathrm{K}$ contents, detection of metabolites, and transcriptome analysis.

\section{Determination of $\mathrm{N}, \mathrm{P}$, and $\mathrm{K}$ contents in D-leaves}

The N, P, and $\mathrm{K}$ contents of the D-leaves of each variety were measure in triplicate as reported earlier [73]. The samples were digested in concentrated $\mathrm{H}_{2} \mathrm{SO}_{4}-\mathrm{H}_{2} \mathrm{O}_{2} . \mathrm{N}$, $\mathrm{P}$, and $\mathrm{K}$ were measured using azometer, spectrophotometer, and a flame photometer, respectively [74].

Differences among the varieties regarding individual $\mathrm{N}$, $\mathrm{P}$, and $\mathrm{K}$ contents were assessed considered significant at $\mathrm{p}<0.05$. The statistical analyses were done in Microsoft Excel ${ }^{\circledR} 2019$.

\section{Transcriptome analysis \\ RNA extraction, library construction, and sequencing}

Total RNA was extracted using Spin Column Plant total RNA Purification kit (Sangon Biotech, Shanghai, China) and the integrity and concentration of RNA was determined using agarose gel electrophoresis and Qubit 2.0 Fluorometer, respectively. Library preparation, quality inspection, and sequencing was done as reported earlier [75].

\section{Bioinformatic analyses of the sequencing data}

High quality reads were filtered to ensure the accuracy of the downstream analyses. To this regard, reads with adapters were removed, removing the paired readers having $\mathrm{N}$ content $>10 \%$, and if the number of low-quality ( $\mathrm{Q}$ $\leq 20$ ) bases in any reads is $>50 \%$ of the bases of the reads. Following this, we determined the sequencing error rate and GC content distribution and the output of sequencing was presented in Microsoft Excel ${ }^{\circledR} 2019$.

The clean reads were compared to the reference genome [76] using HISAT2 [77] and the results were presented in Microsoft Excel ${ }^{\circledR}$ 2019. The gene expression was then quantified as Fragments Per Kilobase of transcript per Million fragments mapped (FPKM) and the distribution of gene expression in each replicate of each variety were presented as expressive box plot. Pearson Correlation Coefficient (PCC) and principal component analysis (PCA) between the expression of varieties and replicates was computed in R using prcomp (www.r-project.org).

The count of the reads was computed using featureCounts followed by Benjamini-Hochberg method to obtain false discovery rate (FDR). Based on the screening criteria i.e., $\mid \log 2$ Fold Change $\mid>=1$, and FDR $<0.05$, the total number of differentially expressed genes (DEGs), number of up/down-regulated genes in each comparison were counted. The graphs and plots for the expression data were computed in Corset (https://code.google. $\mathrm{com} / \mathrm{p} /$ corset-project $/$ ). The DEGs were then functionally annotated and enrichment analysis was performed according to KEGG (Kyoto Encyclopedia of Genes and Genomes (https://www.genome.jb/kegg) [78]. 


\section{Quantitative RT-PCR analysis}

The expression of selected DEGs was evaluated using the qRT-PCR analysis. The Actin gene was used in this experiment as the internal control to standardize the expression results [74]. The PCR reactions and subsequent analysis of the expression data were carried out as reported earlier [74] on a Rotor-Gene 6000 machine (Qiagen, Shanghai, China) using primers designed in Primer 3 (Table 1).

\section{Widely targeted metabolomics Detection of metabolites}

Pineapple D-leaf samples were freeze-dried in a vacuum freeze dryer (scientz-100 F) and crushed in a mixer mil (MM400, Retsch). A $100 \mathrm{mg}$ of lyophilized powder was mixed with $1.2 \mathrm{ml}$ of $70 \%$ methanol, vortexed for $30 \mathrm{~s}$ after every $30 \mathrm{~min}$ for six times and stored at $4{ }^{\circ} \mathrm{C}$ overnight. The samples were centrifuged at $12,000 \mathrm{rpm}$ for $10 \mathrm{~min}$, the extracts were filtered (BLAA-104, $0.22 \mu \mathrm{m}$ ) and processed for UPLC-MS/MS analysis. The UPLC conditions and ESI-Q TRAP-MS/MS analyses were done according to earlier reports [75].

\section{Data analysis}

The PCA on metabolite detection results was performed in $\mathrm{R}$ using prcomp. The hierarchical cluster analysis and PCC were computed in R using pheatmap. For HCA, normalized signal intensities of metabolites (unit variance scaling) are visualized as a color spectrum.

Significantly regulated metabolites between groups were determined by VIP (Variable Importance Projection) $>=1$ and absolute Log2FC (fold change) $>=1$. VIP values were extracted from OPLS-DA result, which also contain score plots and permutation plots, was generated using $R$ package MetaboAnalystR. The data was log transform $(\log 2)$ and mean centering before OPLS-DA. In order to avoid overfitting, a permutation test (200 permutations) was performed.

The identified metabolites were annotated in KEGG and the pathways having significantly accumulated metabolites were fed into metabolite sets enrichment analysis and their significance was determined by hypergeometric test's p-value.

\footnotetext{
Abbreviations

DAM: differentiallyaccumulated metabolites; DEG: differentiallyexpressed gene; FPKM: fragments perkilobase of exon model per million reads mapped; FDR: false discovery rate ; GO: gene ontology; K: potassium; N: nitrogen; P: phosphorus; KEGG: Kyoto Encyclopedia ofGenes and Genomes; PCA: principal component analysis; qRT-PCR: quantitative real-time PCR; TF: transcription factor.
}

\section{Supplementary Information}

The online version contains supplementary material available at https://doi. org/10.1186/s12870-021-03291-0.

Additional file 1.

Additional file 2 .

Acknowledgements

Not applicable.

Authors' contributions

Conceptualization, J.C.; methodology, J.C., H.Z., X.Z.; software, J.C., H.Z., X.Z.; validation, J.C., H.Z., X.Z.; formal analysis, J.C.; investigation, J.C., H.Z., X.Z.; resources, J.C.; data curation, J.C.; writing — original draft preparation, J.C.; writing-review and editing, H.Z., X.Z.; visualization, J.C.; supervision, J.C.; project administration, J.C.; funding acquisition, J.C. All authors have read and agreed to the published version of the manuscript.

\section{Funding}

This work was funded by the Central Public-interest Scientific Institution Basal Research Fund for Innovative Research Team Program of Chinese Academy of Tropical Agricultural Sciences (No.17CXTD-10).

\section{Availability of data and materials}

The raw transcriptome data has been submitted to NCBI SRA under the project number: PRJNA739322.

\section{Declarations}

Ethics approval and consent to participate Not applicable.

\section{Consent for publication}

Not applicable.

\section{Competing interests}

The authors declare no conflict of interest. The funders had no role in the design of the study; in the collection, analyses, or interpretation of data; in the writing of the manuscript, or in the decision to publish the results.

\section{Author details}

${ }^{1}$ Key Laboratory of Tropical Fruit Tree Biology, Ministry of Agriculture, Zhanjiang, Guangdong 524091, China. ${ }^{2}$ South Subtropical Crops Research Institute, Chinese Academy of Tropical Agricultural Sciences, Zhanjiang, Guangdong 524091, China.

Received: 21 June 2021 Accepted: 18 October 2021

Published online: 22 November 2021

\section{References}

1. Sun, G. Pineapple production and research in China. In Proceedings of VII International Pineapple Symposium 902; pp. 79-85.

2. Milošević, T:; Milošević, N. Apple fruit quality, yield and leaf macronutrients content as affected by fertilizer treatment. Journal of soil science and plant nutrition 2015, 15, 76-83

3. Spironello, A.; Quaggio, J.A.; Teixeira, L.A.J.; Furlani, P.R.; Sigrist, J.M.M. Pineapple yield and fruit quality effected by NPK fertilization in a tropical soil. Revista brasileira de fruticultura 2004, 26, 155-159.

4. Amorim, A.V.; Lacerda, C.F.d.; Marques, E.C.; Ferreira, F.J.; Silva Júnior, R.J.d.C.; Andrade Filho, F.L.; Gomes-Filho, E. Micronutrients affecting leaf biochemical responses during pineapple development. Theoretical and Experimental Plant Physiology 2013, 25, 70-78.

5. Hou, W.; Tränkner, M.; Lu, J.; Yan, J.; Huang, S.; Ren, T.; Cong, R.; Li, X. Interactive effects of nitrogen and potassium on photosynthesis and photosynthetic nitrogen allocation of rice leaves. BMC plant biology 2019, 19, 1-13. 
6. Masclaux-Daubresse, C.; Daniel-Vedele, F.; Dechorgnat, J.; Chardon, F.; Gaufichon, L.; Suzuki, A. Nitrogen uptake, assimilation and remobilization in plants: challenges for sustainable and productive agriculture. Annals of botany 2010, 105, 1141-1157.

7. Foyer, C.H.; Noctor, G. Photosynthetic nitrogen assimilation: inter-pathway control and signaling. In Photosynthetic nitrogen assimilation and associated carbon and respiratory metabolism, Springer: 2002; pp. 1-22.

8. José, J.S.; Montes, R.; Cabrera-Bisbal, E. Nitrogen budget in a pineapple crop growing in the Orinoco lowlands. Communications in soil science and plant analysis 2007, 38, 423-447.

9. Sideris, C.; Krauss, B.; Young, H. ASSIMILATION OF AMMONIUM AND NITRATE BY PINEAPPLE PLANTS GROWN IN NUTRIENT SOLUTIONS AND ITS EFFECTS ON NITROGENOUS AND CARBOHYDRATE CONSTITUTENTS. Plant physiology 1938, 13, 489 .

10. Mokhele, B.; Zhan, X.; Yang, G.; Zhang, X. Nitrogen assimilation in crop plants and its affecting factors. Canadian Journal of Plant Science 2012, 92, 399-405.

11. Shin, H.; Shin, H.S.; Chen, R.; Harrison, M.J. Loss of At4 function impacts phosphate distribution between the roots and the shoots during phosphate starvation. The Plant Journal 2006, 45, 712-726.

12. Liu, T.-Y.; Huang, T.-K.; Yang, S.-Y.; Hong, Y.-T.; Huang, S.-M.; Wang, F.-N.; Chiang, S.-F.; Tsai, S.-Y.; Lu, W.-C.; Chiou, T.-J. Identification of plant vacuolar transporters mediating phosphate storage. Nature communications 2016, 7,1-11.

13. Lin, W.-Y.; Huang, T.-K.; Leong, S.J; Chiou, T.-J. Long-distance call from phosphate: systemic regulation of phosphate starvation responses. Journal of Experimental Botany 2014, 65, 1817-1827.

14. Miura, K.; Rus, A.; Sharkhuu, A.; Yokoi, S.; Karthikeyan, A.S.; Raghothama K.G.; Baek, D.; Koo, Y.D.; Jin, J.B.; Bressan, R.A. The Arabidopsis SUMO E3 ligase SIZ1 controls phosphate deficiency responses. Proceedings of the National Academy of Sciences 2005, 102, 7760-7765.

15. Luan, M.; Tang, R.-j.; Tang, Y.; Tian, W.; Hou, C.; Zhao, F.; Lan, W.; Luan, S. Transport and homeostasis of potassium and phosphate: limiting factors for sustainable crop production. Journal of experimental botany 2017, 68, 3091-3105.

16. Yang, T.; Hao, L.; Yao, S.; Zhao, Y.; Lu, W.; Xiao, K. TabHLH1, a bHLH-type transcription factor gene in wheat, improves plant tolerance to Pi and $\mathrm{N}$ deprivation via regulation of nutrient transporter gene transcription and ROS homeostasis. Plant Physiology and Biochemistry 2016, 104, 99-113.

17. Bustos, R.; Castrillo, G.; Linhares, F.; Puga, M.I.; Rubio, V.; Pérez-Pérez, J.; Solano, R.; Leyva, A.; Paz-Ares, J. A central regulatory system largely controls transcriptional activation and repression responses to phosphate starvation in Arabidopsis. PLoS genet 2010, 6, e1001102.

18. Cheong, Y.H.; Pandey, G.K.; Grant, J.J.; Batistic, O.; Li, L.; Kim, B.G.; Lee, S.C.; Kudla, J.; Luan, S. Two calcineurin B-like calcium sensors, interacting with protein kinase CIPK23, regulate leaf transpiration and root potassium uptake in Arabidopsis. The Plant Journal 2007, 52, 223-239.

19. Azeem, F.; Hussain, M.; Hussain, S.; Zubair, M.; Nadeem, H.; Ali, M.A.; Afzal, M.; Siddique, M.H. Genome-wide analysis and expression profiling of potassium transport related genes in Solanum tuberosum. Pakistan Journal of Agricultural Sciences 2021, 58

20. Azeem, F.; Ahmad, B.; Atif, R.M.; Ali, M.A.; Nadeem, H.; Hussain, S.; Manzoor, H.; Azeem, M.; Afzal, M. Genome-wide analysis of potassium transportrelated genes in chickpea (Cicer arietinum L.) and their role in abiotic stress responses. Plant Molecular Biology Reporter 2018, 36, 451-468.

21. Rehman, H.M.; Nawaz, M.A.; Shah, Z.H.; Daur, I.; Khatoon, S.; Yang, S.H.; Chung, G. In-depth genomic and transcriptomic analysis of five $\mathrm{K}+$ transporter gene families in soybean confirm their differential expression for nodulation. Frontiers in plant science 2017, 8, 804.

22. Garcia-Mata, C.; Wang, J.; Gajdanowicz, P.; Gonzalez, W.; Hills, A.; Donald N.; Riedelsberger, J.; Amtmann, A.; Dreyer, I.; Blatt, M.R. A minimal cysteine motif required to activate the SKOR K+ channel of Arabidopsis by the reactive oxygen species $\mathrm{H} 2 \mathrm{O} 2$. Journal of biological chemistry 2010, 285, 29286-29294.

23. Ache, P.; Becker, D.; Ivashikina, N.; Dietrich, P.; Roelfsema, M.R.G.; Hedrich, R. GORK, a delayed outward rectifier expressed in guard cells of Arabidopsis thaliana, is a K+-selective, $\mathrm{K}+$-sensing ion channel. Febs Letters 2000, 486, 93-98.

24. Bassil, E.; Blumwald, E. The ins and outs of intracellular ion homeostasis: NHX-type cation/H+ transporters. Current opinion in plant biology 2014 $22,1-6$
25. Barragán, V.; Leidi, E.O.; Andrés, Z.; Rubio, L.; De Luca, A.; Fernández, J.A.; Cubero, B.; Pardo, J.M. Ion exchangers NHX1 and NHX2 mediate active potassium uptake into vacuoles to regulate cell turgor and stomatal function in Arabidopsis. The Plant Cell 2012, 24, 1127-1142.

26. Dunkel, M.; Latz, A.; Schumacher, K.; Müller, T.; Becker, D.; Hedrich, R. Targeting of vacuolar membrane localized members of the TPK channel family. Molecular Plant 2008, 1, 938-949.

27. Adams, E.; Shin, R. Transport, signaling, and homeostasis of potassium and sodium in plants. Journal of integrative plant biology 2014, 56, $231-249$

28. Tamaki, V.; Mercier, H. Cytokinins and auxin communicate nitrogen availability as long-distance signal molecules in pineapple (Ananas comosus). Journal of plant physiology 2007, 164, 1543-1547.

29. Nguy-Robertson, A.; Peng, Y.; Arkebauer, T.; Scoby, D.; Schepers, J.; Gitelson, A. Using a simple leaf color chart to estimate leaf and canopy chlorophyll a content in Maize (Zea Mays). Communications in Soil Science and Plant Analysis 2015, 46, 2734-2745.

30. Wang, Y.; Wang, D.; Shi, P.; Omasa, K. Estimating rice chlorophyll content and leaf nitrogen concentration with a digital still color camera under natural light. Plant methods 2014, 10,1-11.

31. Prilianti, K.R.; Yuwono, S.P.; Adhiwibawa, M.A.; Prihastyanti, M.N.; Limantara, L.; Brotosudarmo, T.H. Automatic leaf color level determination for need based fertilizer using fuzzy logic on mobile application: A model for soybean leaves. In Proceedings of 2014 6th International Conference on Information Technology and Electrical Engineering (ICITEE); pp. 1-6.

32. Lea, P.; Forde, B. The use of mutants and transgenic plants to study amino acid metabolism. Plant, cell \& environment 1994, 17, 541-556.

33. Tercé-Laforgue, T.; Bedu, M.; Dargel-Grafin, C.; Dubois, F.; Gibon, Y.; Restivo, F.M.; Hirel, B. Resolving the role of plant glutamate dehydrogenase: II. Physiological characterization of plants overexpressing the two enzyme subunits individually or simultaneously. Plant and Cell Physiology 2013, 54, 1635-1647.

34. Stigter, K.A.; Plaxton, W.C. Molecular mechanisms of phosphorus metabolism and transport during leaf senescence. Plants 2015, 4, 773-798.

35. Shen, J.; Yuan, L.; Zhang, J.; Li, H.; Bai, Z.; Chen, X.; Zhang, W.; Zhang, F. Phosphorus dynamics: from soil to plant. Plant physiology 2011, 156, 997-1005.

36. Schachtman, D.P.; Reid, R.J.; Ayling, S.M. Phosphorus uptake by plants: from soil to cell. Plant physiology 1998, 116, 447-453.

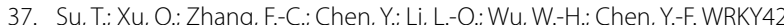
modulates phosphate homeostasis through regulating phosphate translocation and acquisition in Arabidopsis. Plant Physiology 2015, 167, 1579-1591.

38. Chen, Y.-F.; Li, L.-Q.; Xu, Q.; Kong, Y.-H.; Wang, H.; Wu, W.-H. The WRKY6 transcription factor modulates PHOSPHATE1 expression in response to low Pi stress in Arabidopsis. The Plant Cell 2009, 21, 3554-3566.

39. Briskin, D.P.; Gawienowski, M.C. Role of the plasma membrane H+-ATPase in K+ transport. Plant physiology 1996, 111,1199-1207.

40. Evans, J.R.; Clarke, V.C. The nitrogen cost of photosynthesis. Journal of Experimental Botany 2019, 70, 7-15.

41. Field, C. Allocating leaf nitrogen for the maximization of carbon gain: leaf age as a control on the allocation program. Oecologia 1983, 56, 341-347.

42. Hao, D.-L.; Zhou, J.-Y.; Yang, S.-Y.; Qi, W.; Yang, K.-J.; Su, Y.-H. Function and Regulation of Ammonium Transporters in Plants. International Journal of Molecular Sciences 2020, 21, 3557.

43. Jiang, J.; Zhao, J.; Duan, W.; Tian, S.; Wang, X.; Zhuang, H.; Fu, J.; Kang, Z. TAAMT2; 3a, a wheat AMT2-type ammonium transporter, facilitates the infection of stripe rust fungus on wheat. BMC plant biology 2019, 19, 1-11.

44. Campbell, W.H. Nitrate reductase and its role in nitrate assimilation in plants. Physiologia Plantarum 1988, 74, 214-219.

45. Temple, S.J.; Vance, C.P.; Gantt, J.S. Glutamate synthase and nitrogen assimilation. Trends in plant science 1998, 3, 51-56.

46. Miflin, B.J.; Lea, P.J. The pathway of nitrogen assimilation in plants. Phytochemistry 1976, 15, 873-885.

47. Pietrzykowska, M.; Suorsa, M.; Semchonok, D.A.; Tikkanen, M.; Boekema, E.J.; Aro, E.-M.; Jansson, S. The light-harvesting chlorophyll a/b binding proteins Lhcb1 and Lhcb2 play complementary roles during state transitions in Arabidopsis. The Plant Cell 2014, 26, 3646-3660. 
48. Fernández, E.; Llamas, Á.; Galván, A. Nitrogen assimilation and its regulation. In The Chlamydomonas sourcebook, Elsevier: 2009; pp. 69-113.

49. King, J.E.; Gifford, D.J. Amino acid utilization in seeds of loblolly pine during germination and early seedling growth (I. arginine and arginase activity). Plant Physiology 1997, 113, 1125-1135.

50. Meinnel, T.; Schmitt, E.; Mechulam, Y.; Blanquet, S. Structural and biochemical characterization of the Escherichia coli argE gene product. Journal of bacteriology 1992, 174, 2323-2331.

51. Wang, D.; Lv, S.; Jiang, P.; Li, Y. Roles, regulation, and agricultural application of plant phosphate transporters. Frontiers in Plant Science 2017, 8, 817.

52. Barbosa, T.M.B.; Santos, J.Z.L.; Tucci, C.A.F.; Da Silva, S.V.; Cardoso, A.A.d.S. Pereira, B.F.F. Phosphorus sources: effects on growth and phosphorus fractions of Curauá (Ananas erectifolius LB Smith). Communications in Soil Science and Plant Analysis 2015, 46, 1200-1211.

53. Ahmed, O.; Husni, M.; Hanafi, M.; Anuar, A.; Omar, S.S. Phosphorus fertilizer use in pineapple cultivation with in situ residues burning on organic soils. Communications in soil science and plant analysis 2007, 38, 1243-1254.

54. Mustaffa, M. Effect of phosphorus application on fruit yield quality and leaf nutrient content of Kew pineapple. Fruits (France) 1989.

55. Takabatake, R.; Hata, S.; Taniguchi, M.; Kouchi, H.; Sugiyama, T.; Izui, K. Isolation and characterization of cDNAs encoding mitochondrial phosphate transporters in soybean, maize, rice, and Arabidopsis. Plant molecular biology 1999, 40, 479-486.

56. Gu, M.; Chen, A.; Sun, S.; Xu, G. Complex regulation of plant phosphate transporters and the gap between molecular mechanisms and practical application: what is missing? Molecular Plant 2016, 9, 396-416.

57. Guo, M.; Ruan, W.; Li, C.; Huang, F.; Zeng, M.; Liu, Y.; Yu, Y.; Ding, X.; Wu, Y.; Wu, Z. Integrative comparison of the role of the PHOSPHATE RESPONSE1 subfamily in phosphate signaling and homeostasis in rice. Plant Physio/ogy 2015, 168, 1762-1776.

58. Rubio, V.; Linhares, F.; Solano, R.; Martín, A.C.; Iglesias, J.; Leyva, A.; Paz-Ares, J. A conserved MYB transcription factor involved in phosphate starvation signaling both in vascular plants and in unicellular algae. Genes \& development 2001, 15, 2122-2133

59. Kc, S.; Liu, M.; Zhang, Q.; Fan, K.; Shi, Y.; Ruan, J. Metabolic changes of amino acids and flavonoids in tea plants in response to inorganic phosphate limitation. International journal of molecular sciences 2018, 19, 3683.

60. Li, S.; Peng, F.; Xiao, Y.; Gong, Q.; Bao, Z.; Li, Y.; Wu, X. Mechanisms of high concentration valine-mediated inhibition of peach tree shoot growth. Frontiers in Plant Science 2020, 11.

61. Shabala, S. Regulation of potassium transport in leaves: from molecular to tissue level. Annals of Botany 2003, 92, 627-634

62. Trchounian, A.; Kobayashi, H. Kup is the major K+ uptake system in Escherichia coli upon hyper-osmotic stress at a low pH. FEBS letters 1999, 447, 144-148.

63. Zakharyan, E.; Trchounian, A. K+ influx by Kup in Escherichia coli is accompanied by a decrease in H+ efflux. FEMS microbiology letters 2001, 204, 61-64.

64. Sharma, T.; Dreyer, I.; Riedelsberger, J. The role of K+ channels in uptake and redistribution of potassium in the model plant Arabidopsis thaliana. Frontiers in plant science 2013, 4, 224.
65. Jarratt-Barnham, E.; Wang, L.; Ning, Y.; Davies, J.M. The Complex Story of Plant Cyclic Nucleotide-Gated Channels. International Journal of Molecular Sciences 2021, 22, 874.

66. Zhang, M.; Cao, Y.; Wang, Z.; Wang, Z.q.; Shi, J.; Liang, X.; Song, W.; Chen, Q.; Lai, J.; Jiang, C. A retrotransposon in an HKT1 family sodium transporter causes variation of leaf $\mathrm{Na}+$ exclusion and salt tolerance in maize. NeW Phytologist 2018, 217, 1161-1176.

67. Lan, W.-Z.; Lee, S.-C.; Che, Y.-F.; Jiang, Y.-Q.; Luan, S. Mechanistic analysis of AKT1 regulation by the CBL-CIPK-PP2CA interactions. Molecular Plant 2011, 4, 527-536

68. Park, S.; Cheng, N.H.; Pittman, J.K.; Yoo, K.S.; Park, J.; Smith, R.H.; Hirschi, K.D. Increased calcium levels and prolonged shelf life in tomatoes expressing Arabidopsis H+/Ca2+ transporters. Plant Physiology 2005, 139, 1194-1206.

69. Van Kleeff, P.; Gao, J.; Mol, S.; Zwart, N.; Zhang, H.; Li, K.; De Boer, A. The Arabidopsis GORK K+-channel is phosphorylated by calcium-dependent protein kinase 21 (CPK21), which in turn is activated by 14-3-3 proteins. Plant Physiology and Biochemistry 2018, 125, 219-231.

70. Lefoulon, C.; Boeglin, M.; Moreau, B.; Véry, A.-A.; Szponarski, W.; Dauzat, M.; Michard, E.; Gaillard, I.; Chérel, I. The Arabidopsis AtPP2CA protein phosphatase inhibits the GORK K+ efflux channel and exerts a dominant suppressive effect on phosphomimetic-activating mutations. Journal of Biological Chemistry 2016, 291, 6521-6533.

71. Zeng, J.; Quan, X.; He, X.; Cai, S.; Ye, Z.; Chen, G.; Zhang, G. Root and leaf metabolite profiles analysis reveals the adaptive strategies to low potassium stress in barley. BMC plant biology 2018, 18, 1-13.

72. Wang, M.; Zheng, Q.; Shen, Q.; Guo, S. The critical role of potassium in plant stress response. International journal of molecular sciences 2013, 14, 7370-7390.

73. Bataglia, O.; Teixeira, J.; Furlani, P.; Furlani, A.; Gallo, J. Métodos de análise química de plantas; IAC Campinas: 1978

74. Lu, R. Analytical Methods of Soil Agricultural Chemistry. China Agricultural Science and Technology Press, Beijing, China. 1999.

75. Chen, L.; Wu, Q.; He, W.; He, T.; Wu, Q.; Miao, Y. Combined De Novo Transcriptome and Metabolome Analysis of Common Bean Response to Fusarium oxysporum f. sp. phaseoli Infection. International journal of molecular sciences 2019, 20,6278.

76. Ming, R.; VanBuren, R.; Wai, C.M.; Tang, H.; Schatz, M.C.; Bowers, J.E.; Lyons, E.; Wang, M.-L.; Chen, J.; Biggers, E. The pineapple genome and the evolution of CAM photosynthesis. Nature genetics 2015, 47, 1435-1442.

77. Kim, D.; Paggi, J.M.; Park, C.; Bennett, C.; Salzberg, S.L. Graph-based genome alignment and genotyping with HISAT2 and HISAT-genotype. Nature biotechnology 2019, 37, 907-915.

78. Kanehisa, M.; Goto, S. KEGG: kyoto encyclopedia of genes and genomes. Nucleic acids research 2000, 28, 27-30.

\section{Publisher's Note}

Springer Nature remains neutral with regard to jurisdictional claims in published maps and institutional affiliations.
Ready to submit your research? Choose BMC and benefit from:

- fast, convenient online submission

- thorough peer review by experienced researchers in your field

- rapid publication on acceptance

- support for research data, including large and complex data types

- gold Open Access which fosters wider collaboration and increased citations

- maximum visibility for your research: over $100 \mathrm{M}$ website views per year

At BMC, research is always in progress.

Learn more biomedcentral.com/submissions 